\title{
Tendencias sociodemográficas y segregación socioespacial en Los Ángeles, Chile ${ }^{1}$
}

\author{
Gerardo Azócar², Cristián Henríquez³ ${ }^{3}$ Claudia Valenzuela ${ }^{4}$ y \\ Hugo Romero ${ }^{5}$
}

\begin{abstract}
RESUMEN
Esta investigación identifica los principales procesos demográficos y sociales que afectan a la población de tres sectores de la ciudad de Los Ángeles, vinculando dichos comportamientos con los nuevos patrones de urbanización y crecimiento urbano observados en las últimas décadas, especialmente la denominada segregación socioespacial urbana. Se analiza el peso que adquiere el factor demográfico en la conformación o producción del espacio social. Se reconoce la importancia de realizar estudios empíricos en ciudades intermedias fuertemente impactadas por el proceso de globalización económica y por diversas políticas públicas, principalmente en materia de vivienda social e infraestructura vial, identificando aquellos factores específicos y aquellos de naturaleza más general que han orientado su evolución más reciente. Se asume, como una de las principales hipótesis de trabajo, que ciertas configuraciones o perfiles sociodemográficos de la población tienen un claro patrón de distribución espacial en la ciudad, como la concentración de la pobreza y la vulnerabilidad social.
\end{abstract}

Palabras clave: Segregación socioespacial, factores sociodemográficos, ciudades intermedias, Santa María de Los Ángeles.

\begin{abstract}
In this paper the behavior of socio-demographic variables in urban and rural zones of Los Ángeles city is analyzed, Biobío region, Chile. The main demographic and social processes are identified in relationship with the fast urban growth of the city, the land use patterns and the socio-spatial segregation processes. A relation between demographic variables and social spaces were defined, mainly in the urban fringe. The importance of empirical studies is recognized in the mid cities which in the last decades have been impact by the economic globalization process and the public policies, mainly in the matter of social house and road infrastructure, recognizing those specific factors and those of nature more general than they have guided its recent urban change. It is assumed, like one of the main hypotheses, that certain demographic and social configurations show a clearly spatial pattern in the city, like the concentration of the poverty and the social vulnerability in some urban areas.
\end{abstract}

Key words: Sociospatial segregation, sociodemografics factors, mid-cities, Santa María de Los Ángeles.

1 Artículo recibido el 7 de diciembre de 2007 y aceptado el 2 de julio de 2008.

2 Centro de Ciencias Ambientales EULA-Chile, Universidad de Concepción (Chile). E-mail: gazocar@udec.cl
3 Instituto de Geografía, Pontificia Universidad Católica de Chile (Chile). E-mail: cghenriq@uc.cl

4 Escuela de Sociología, Universidad de Concepción (Chile). E-mail: claudval@udec.cl

5 Departamento de Geografía, Universidad de Chile (Chile).E-mail: hromero@abello.dic.uchile.cl 
El proceso de urbanización en los países de América Latina, hasta la década de 1970, estuvo relacionado con el alto crecimiento demográfico de la población, junto con elevados índices de fecundidad, migraciones rural-urbanas y la concentración cada vez mayor de la población en grandes ciudades o áreas metropolitanas (Pinto da Cunha, 2002). Otro factor que ha influido ha sido la industrialización sustitutiva de importaciones, que implicó la concentración de actividades productivas en las ciudades, y la modernización de las relaciones capitalistas en el campo, que influyó sobre la migración urbano-rural, como también en la modificación continua de los patrones de producción, distribución y consumo, pasando desde una producción agrícola a una economía industrial primaria $y$, en general, a un desarrollo basado en el capital financiero y los servicios especializados (Balbo et al., 2003). Para este último autor, el proceso de transformación productiva estaría directamente vinculado con el proceso de urbanización, concentración de la población y crecimiento de las ciudades, no solo en áreas metropolitanas o grandes urbes, sino también en ciudades intermedias.

Las ciudades intermedias se han consolidado como centros, sobre una base productiva y sociocultural que les permite ser competitivas, además de desarrollar ventajas comparativas como la adición de valor agregado y de tecnología en la exportación de materias primas. Ello ha significado que este tipo de ciudades, junto a sus territorios o áreas de influencia, hayan generado economías de aglomeración o clusters territoriales, transformándose, paulatinamente, en nodos de dichos sistemas. En Chile, el rápido crecimiento de estas ciudades ha ido acompañado del surgimiento de nuevas formas de urbanización, con importantes efectos ambientales y socioeconómicos (Azócar et al., 2007; Henríquez y Azócar, 2007; Henríquez et al., 2006), asociados a profundas transformaciones demográficas, como la reducción del crecimiento, el sostenido descenso de la fecundidad y la mortalidad, la remodelación de la estructura etaria y el envejecimiento de la población, especialmente en áreas o centros urbanos.
Para Balbo et al. (2003), el desplazamiento de población rural a centros urbanos y la denominada urbanización del campo, habrían acentuado y concentrado no solo la pobreza en las ciudades, sino también en nuevos núcleos urbanos en zonas rurales, la mayor parte de los cuales se han generado y desarrollado al margen de políticas de planificación urbana y territorial. En definitiva, la urbanización de la pobreza ha generado ciudades divididas, fragmentadas y segregadas desde un punto de vista espacial, con problemas de conectividad e integración entre sus barrios y sus residentes. En este sentido, la dinámica urbana, tanto desde el punto de vista físico como sociocultural, tendería más bien a excluir-privatizar antes que a integrar la sociedad. Las evidencias empíricas indican que las ciudades de América Latina han desarrollado, en las últimas décadas, nuevas estructuras o nuevos artefactos urbanos, condicionados y modulados por los requerimientos de la globalización (De Mattos, 2001), y nuevas formas y patrones de urbanización (Azócar et al., 2007; Henríquez et al., 2006; Aguayo et al., 2007; Romero et al., 2005; Hidalgo y Borsdorf, 2005).

Esta urbanización acelerada y espontánea, regulada la mayoría de las veces por el mercado inmobiliario y por políticas públicas, ha agudizado la diferenciación sociodemográfica y socioespacial dentro de las ciudades, con áreas preferenciales para la localización de usos residenciales exclusivos, actividades industriales y verdaderos enclaves de pobreza, marginalidad y exclusión (Rodríguez y Villa, 1998; Hidalgo, 2004). A su vez, los centros históricos o tradicionales de las ciudades han ido paulatinamente, perdiendo su rol y vitalidad, en pos de nuevas centralidades, ubicadas en zonas más alejadas, dotadas con mejores servicios y entornos sociales prestigiosos. El rápido crecimiento urbano no solo ha significado cambios en las funciones y morfología de las ciudades, sino también una profunda reconfiguración del medio rural, con una nueva representación social del campo, especialmente porque las áreas rurales son ahora percibidas en términos de sus paisajes, y no solo en función de su productividad como tierras agrícolas (Antrop, 2000; Floysand \& Jakobsen, 2007). Conceptos tales como rural landscape, sce- 
nery or scenic amenity o attractive physical environments han sido identificados como importantes factores de atracción de inversiones y población hacia zonas rurales, especialmente en el límite de espacios urbanos construidos (González, 1994; Antrop, 2000; Romero, 2006).

Los procesos mencionados como también sus consecuencias urbanas, sociales, económicas y ambientales han sido analizados en grandes ciudades o áreas metropolitanas de América Latina (Rodríguez y Villa, 1998; Hidalgo et al., 2003; Romero et al., 2005; Sabatini, 2000; Segura, 2003). Los factores relevantes que han orientado los procesos de crecimiento urbano han incluido la ocupación informal de suelos y la conformación de asentamientos populares, políticas y gestión pública destinada a proveer viviendas sociales a los grupos de menores ingresos y el uso especulativo del suelo por parte de empresas inmobiliarias (Rodríguez y Villa, 1998).

Para el caso de las ciudades chilenas y, especialmente, para el área metropolitana de Santiago y algunas ciudades intermedias de la zona centro-sur, se ha identificado una clara relación entre el crecimiento de las ciudades y la intensificación de los procesos de diferenciación, exclusión y segregación social y espacial, especialmente para los usos y/o actividades residenciales e industriales (Sabatini, 1998; Romero y Toledo, 1998; Borsdorf, 2000; Rovira, 2000; Toledo et al., 2000; Azócar et al., 2003; Azócar et al., 2007). Ello ha tenido significativos efectos sobre las redes de infraestructura y de servicios, ocupación de suelos agrícolas de alta productividad y la intensificación de la fragmentación social (Hidalgo et al., 2003; Henríquez et al., 2006). Desde un punto de vista morfológico, muchas ciudades chilenas muestran un uso del suelo irregular y discontinuo, con una tendencia más bien a la extensión que a la densificación, y con zonas céntricas y próximas al centro con espacios urbanos prácticamente vacuos y sin desarrollar (Rojas et al., 2006; Aguayo et al., 2007; Henríquez et al., 2006).

De particular importancia han sido los programas de vivienda social impulsados por el Estado, los cuales, históricamente, han contribuido a acentuar la segregación social y espacial a gran escala. Uno de los resultados más visibles de esta política ha sido la localización de las viviendas sociales en los suelos urbanos de menor costo y con notorias restricciones o limitaciones ambientales para su urbanización, en zonas urbanas adyacentes o próximas a sectores donde ya residían otros grupos sociales de ingresos bajos (Sabatini, 2000). En cierto modo, el Estado ha favorecido el aislamiento y exclusión de los más pobres, agudizando procesos y patologías sociales, como la delincuencia y la estigmatización y, a la vez, desvinculando a grandes sectores de la población de los mercados del trabajo, bienes y servicios, limitando con ello las posibilidades de aprovechar la estructura de oportunidades de la sociedad, en la esfera del Estado, el mercado y la sociedad civil (Segura, 2003). Dichos barrios o zonas urbanas, generalmente localizados en zonas periféricas de la ciudad, se han transformado en lugares poco seguros, acentuándose los factores o condiciones de riesgo social que conducen a la pobreza (Filgueira y Peri, 2004).

En una perspectiva más alentadora, sería posible afirmar que las condiciones de vida de los grupos sociales más pobres en Chile han mejorado notoriamente a partir de 1990. Sin embargo, la distribución espacial de la pobreza en las ciudades, como también el comportamiento de algunos indicadores sociodemográficos, no ha cambiado mucho en los últimos años (Rodríguez, 2001; Ortiz y Morales, 2002). Si bien estas políticas de Estado, aplicadas de manera más o menos homogénea en todo el país, han permitido paliar importantes déficit habitacionales y regularizar la ocupación del suelo urbano en muchas ciudades, no es menos cierto que han contribuido a reforzar un patrón urbano de crecimiento marcadamente diferenciado, fragmentado y segmentado, con efectos ambientales y sociales negativos. Ciudades como Chillán, Los Ángeles, Temuco y Concepción, presentan procesos y tendencias de crecimiento similares, pero, a la vez, ciertos factores locales que definen, inclusive, procesos opuestos o de diferente magnitud entre cada una de ellas (Azócar, et al., 2007; Aguayo et al., 2007; Henríquez et al., 2006). 
Un buen ejemplo de acciones estatales destinadas a crear espacios integrados espacialmente a la trama urbana de la ciudad, aprovechando de mejorar áreas degradadas y favorecer las potencialidades de aumentar la integridad social, lo constituye el proyecto Ribera Norte, localizado en esa posición del río Biobío, en la ciudad de Concepción. Dicho proyecto consideró la construcción de defensas fluviales, infraestructura vial, equipamientos, parques urbanos, viviendas y la conformación de nuevos barrios, reubicando la población en las mismas zonas urbanas degradadas y desvalorizadas que ocupaban en la ribera norte del río Biobío, valorando la existencia de este capital social y limitando la ocurrencia de un proceso de gentrificación y la consiguiente expulsión de sus habitantes originales (Rojas et al., 2006; Zunino, 2005; Atria, 2008). En síntesis, el tipo de desarrollo urbano, prevaleciente en Chile desde la década de 1970, ha tenido efectos sobre la segregación socioespacial, especialmente en relación con la concentración de población pobre en ciertas áreas periféricas de las ciudades, elevados costos sociales, económicos y ambientales asociados, principalmente, al transporte y a las mayores distancias entre los sitios de residencia a los lugares de trabajo y centros de servicios.

Desde otra perspectiva, no existen muchos trabajos que vinculen o relacionen el proceso de segregación social y espacial urbana con el comportamiento sociodemográfico de la población. Por una parte, el estudio de la vulnerabilidad social se ha centrado en los cambios en la estructura demográfica en el seno del comportamiento del grupo familiar y, por otro lado, en el conocimiento de las pautas reproductivas de los hogares, el número de hijos, su espaciamiento y, particularmente, en los grados y tipos de dependencia demográfica (Filgueira y Peri, 2004). De este modo, Ios análisis han estado orientados a delimitar escenarios de riesgo sociodemográfico, asociados a procesos demográficos de larga duración; identificar sesgos sociales cuando los riesgos se materializan y evaluar la capacidad de respuesta y de habilidad de adaptación de las comunidades, hogares y personas más propensos a estos riesgos, en el marco del proceso de transición demográfica que experimentan los países de América Latina.

En el caso de Chile, es posible identificar importantes diferencias en el comportamiento de algunos indicadores demográficos, tanto en áreas urbanas como rurales, como también entre grupos de población de diferente condición social y económica. Lo anterior, entre otros aspectos, se expresa en antiguas y nuevas vulnerabilidades sociales, las cuales pueden coexistir dentro de los mismos países, regiones y ciudades. La infantilización de la dependencia demográfica, junto al remodelamiento de los grupos etáreos y el surgimiento de nuevos grupos de riesgo, como los adultos mayores o las madres adolescentes, son procesos aún paralelos que pueden ser observados en muchos países de América Latina. Para Busso (2001), estos procesos no son más que la tradicional expresión de los desequilibrios, de toda naturaleza, que han marcado el desarrollo de los países de la región.

Dentro de este contexto, en esta investigación se pretenden analizar las relaciones entre variables sociodemográficas y espacios sociales en áreas urbanas y rurales de la ciudad de Santa María de Los Ángeles que, en los últimos años, ha experimentado un rápido crecimiento y segregación socioespacial, identificando y describiendo las actuales configuraciones sociodemográficas y su relación con el desarrollo urbano más reciente del área de estudio. Como hipótesis de trabajo, se asume que: i) La diferenciación urbana y social observada puede ser interpretada como el resultado de procesos demográficos, económicos, culturales, políticos y de acciones de planificación local; ii) El perfil sociodemográfico de la población y hogares, estaría directamente relacionado con su distribución espacial y condición socioeconómica; iii) La segregación socioespacial de la población, puede ser explicada, en parte, por la configuración sociodemográfica específica de sus residentes, familias y barrios y; iv) El comportamiento sociodemográfico, adquiere un claro patrón de distribución espacial y, a la vez, expresa diferentes vulnerabilidades y riesgos sociales. 


\section{Área de estudio}

La comuna de Los Ángeles se ubica en la Depresión Intermedia o Valle Central de Chile, a $130 \mathrm{~km}$ al sureste de la ciudad de Concepción, capital de la Región del Biobío, y a unos $500 \mathrm{~km}$ al sur de Santiago (Figura $N^{\circ} 1$ ). A su vez, la ciudad de Los Ángeles es la capital de la provincia de Biobío y de la comuna de Los Ángeles, con una superficie comunal de $1.748 \mathrm{~km}^{2}$. En 1992, la población comunal alcanzaba a 140.535 , mientras que el año 2002 esta cifra llegaría a 166.556 habitantes, de los cuales un $74,2 \%$ habitaban en zonas urbanas (123.445) y un $25,8 \%$ en zonas rurales (43.111). La variación intercensal de la población comunal entre los Censos de 1992 y 2002 fue de $18,5 \%$ con una tasa global de fecundidad de $1,5 \%$.

Entre los Censos de 1940 y 1992 se observa un proceso de concentración de la población comunal en la ciudad capital de la provincia de Biobío, es decir, Los Ángeles, que pasa de un $40,1 \%$ en 1940 , a un $67,4 \%$ en 1992. Lo anterior evidencia un importante crecimiento de la población comunal y, especialmente, de la ciudad de Los Ángeles, inclusive superior al observado en la Región Metropolitana de Santiago. Efectivamente, entre los años 1992 y 2002, la comuna presenta una tasa de crecimiento anual de $2,6 \%$, mientras que el Gran Santiago solo alcanza a $1,3 \%$. En ese mismo periodo, Los Ángeles aumentó su superficie urbana a una tasa anual de 4,9\%, mientras que el Gran Santiago lo hacía a 4,3\% (Henríquez et al., 2006).

Cabe señalar que Los Ángeles, junto con Chillán, son las principales ciudades del sistema urbano regional del Biobío, después de la conurbación Concepción-Talcahuano y que, en sus respectivas provincias, son los centros urbanos de mayor jerarquía funcional, aspecto que les permite satisfacer las demandas de bienes y servicios de los centros menores, urbanos y rurales, localizados en sus áreas de influencia y sus territorios adyacentes.

Desde un punto de vista socioeconómico, el $21,4 \%$ de la población comunal (37.715 habitantes) ha sido clasificada por MIDEPLAN (2005) en condición de pobreza y un $4,5 \%$ en situación de indigencia $(7.928$ personas). En términos de desarrollo económico y productivo, la provincia de Biobío, servida por la ciudad de Los Ángeles, ha experimentado importantes transformaciones territoriales conducidas, principalmente, por

Figura $N^{\circ} 1$

LOCALIZACIÓN DEL ÁREA DE ESTUDIO

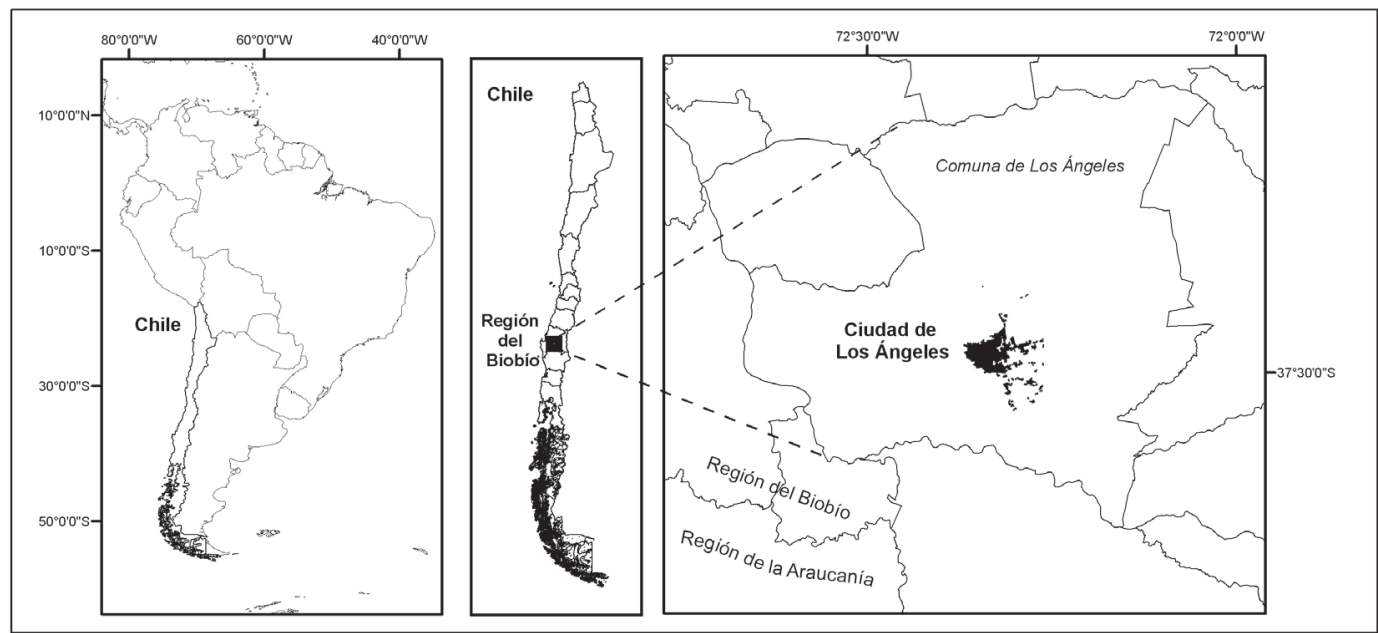

Fuente: Elaboración propia. 
la inserción de la comuna y de su capital provincial, en mercados nacionales e internacionales de bienes y servicios de los rubros forestal-industrial, agrícola y agroindustrial, además de su consolidación como centro administrativo regional y provincial, nodo urbano de servicios y de transferencia y transformación de recursos naturales. Estos roles, indudablemente, han tensado el crecimiento de la ciudad en las últimas décadas, como también la movilidad de la población rural y el desarrollo de inversiones públicas y privadas.

Producto del posicionamiento de Los Ángeles como ciudad primada en el sistema de centros urbanos de la provincia del Biobío, se ha observado un importante desarroIlo de proyectos inmobiliarios privados y públicos, cuyo objetivo fundamental ha sido, por una parte, satisfacer las demandas de viviendas sociales $y$, por otro lado, los requerimientos específicos de localización residencial para grupos de ingresos medios y altos. Un rasgo distintivo de este proceso ha sido la confinación de grupos sociales, de bajos ingresos, a ciertos sectores de la ciudad, provocando su marginación y segregación espacial respecto a la red de servicios, equipamientos y a otros grupos sociales de mayores ingresos. Estos últimos han tendido, paulatinamente, a localizarse cada vez más lejos del centro, fundamentalmente en exclusivos condominios privados y parcelas de agrado, ubicados en medio de áreas rurales.

\section{Metodología}

El foco de la investigación está orientado a la identificación de los factores causales de la diferenciación socioespacial urbana, a partir del análisis de variables sociodemográficas y económicas. De este modo, el análisis consideró tres distritos censales, urbanos y rurales, de la ciudad y comuna de Los Ángeles: Humán, Avenida Maipú y Estación Arrayán (Figura $N^{\circ} 2$ ), representativos del crecimiento urbano más reciente y de ciertas configuraciones y vulnerabilidades sociodemográficas, explicativas del denominado proceso de segregación social y espacial de la ciudad. Desde esta perspectiva, se asume como hipótesis que ciertas configuraciones sociodemográficas, junto con ser ex- presión de vulnerabilidades sociales, representan, geográficamente, la desigualdad social en la ciudad, promoviendo el aislamiento y separación de los individuos y generando patrones normativos y subculturas marginales (Kaztman, 2002; Azócar et al., 2003; Borsdorf, 2003).

Si bien los procesos antes mencionados han sido descritos para grandes ciudades o áreas metropolitanas de nuestro país, no existe suficiente evidencia empírica respecto del comportamiento de las ciudades intermedias, razón por la cual, en esta investigación, se ha establecido una relación ente variables demográficas y espacios sociales, o si se prefiere, se ha determinado el peso que adquiere el factor demográfico en la conformación o producción del espacio social. Como se mencionó, el estudio se realizó en tres distritos censales de la ciudad, los cuales presentan las siguientes características: i) Han sido receptores, en los últimos años, de importantes contingentes de población, provenientes de otros sectores urbanos de la ciudad o bien de zonas rurales de la comuna; ii) Se observa, en dichas áreas, un importante crecimiento urbano, continuo y no continuo, especialmente a través de proyectos habitacionales para grupos sociales de ingresos medios y bajos, como también condominios, parcelas de agrado y actividades industriales y agroindustriales y; iii) Representan áreas de transición y de cambio, respecto de usos del suelo, distribución y localización de equipamientos, localización de población y orientación de actividades económicas, principalmente agropecuarias y de servicios.

La caracterización sociodemográfica consideró las siguientes tasas e indicadores calculados y contenidos en los censos de población de los años 1992 y 2002: densidad de población, tasa de crecimiento de la población, estructura etaria, tasa global de fecundidad, índice de envejecimiento, índice de dependencia demográfica, población económicamente activa total y según sexo, desempleo, nivel de escolaridad de los jefes de familia y actividades económicas de la población según sexo.

Adicionalmente, cuatro diferentes tipologías de espacios sociales fueron definidos 

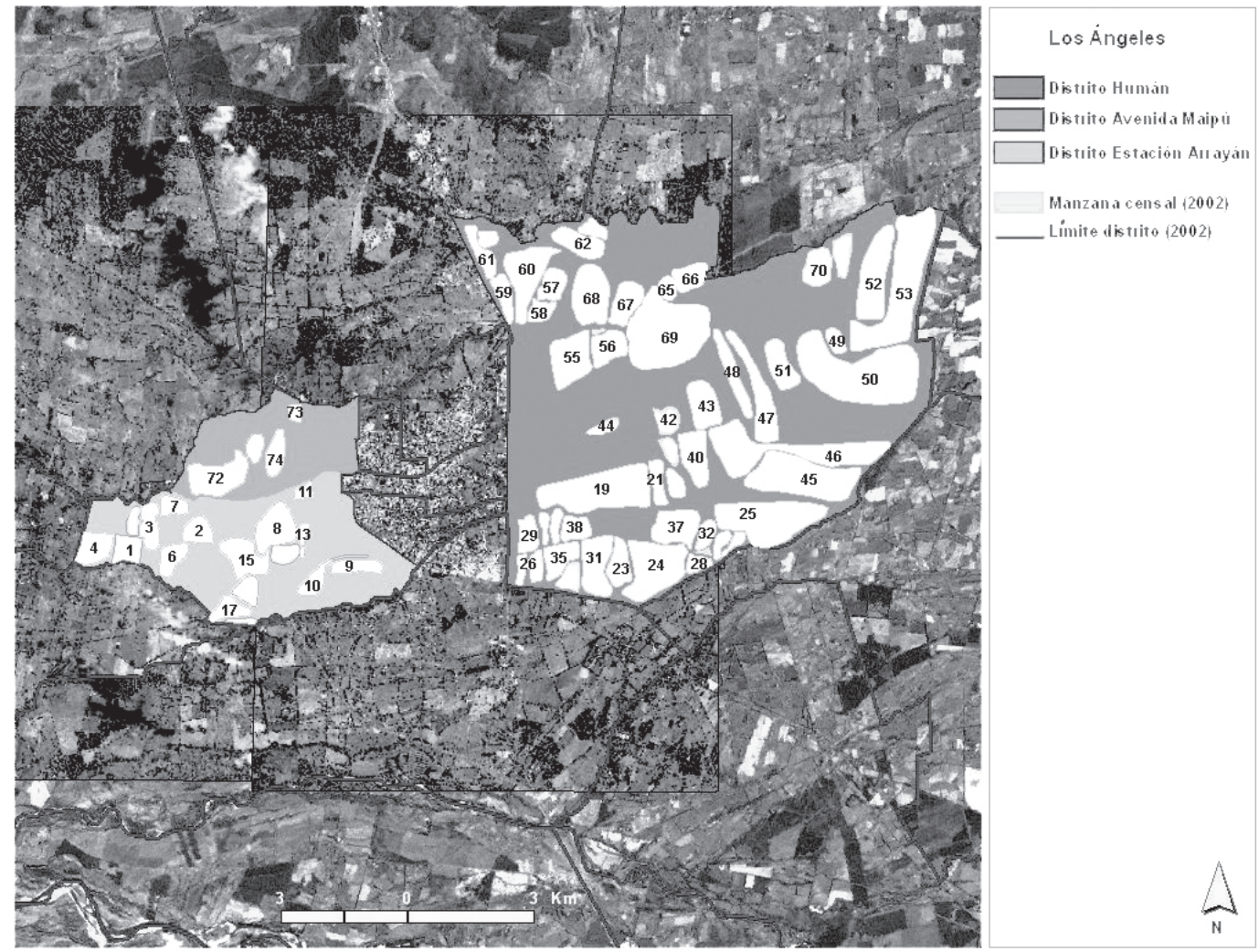

Fuente: Elaboración propia sobre la base de imágenes satelitales IKONOS (2006) y coberturas digitales MIDEPLAN (2005).

sobre la base de la elaboración e interpretación del indicador de Necesidades Básicas Insatisfechas $(\mathrm{NBI})$, propuesto por CEPAL (ILPES, 1995). Este último indicador permitió diferenciar niveles de desarrollo socioeconómico de la población, para cada distrito censal, y se calculó en términos relativos respecto al total de población y/o viviendas de la unidad censal considerada. Para su elaboración, se consideraron las siguientes variables: a) Estructura, tipo, materiales de las paredes, materiales del techo, materiales del piso y alumbrado de las viviendas; b) Agua potable; c) Alcantarillado y; d) Hacinamiento o la existencia de más de tres personas por dormitorio. A su vez, la vulnerabilidad se midió como la relación de dependencia entre el conjunto de miembros de la familia respecto a las personas activas ocupadas y la educación del jefe de hogar, con cuatro o menos años de instrucción escolar. Finalmente, el cruce de ambos tipos de variables, carencias físicas de la vivienda y vulnerabilidad, permitió clasificar los hogares y la población en las siguientes categorías:

- Población en condición de pobreza crítica: Grupo de población que presenta las siguientes características: viviendas con carencias físicas (precariedad de la construcción y de servicios básicos); hogares en que existen más de tres dependientes por persona activa y cuyo jefe de familia posee cuatro años o menos de instrucción escolar. Representa la denominada pobreza dura o indigencia.

- Población en condición de pobreza inercial: Grupo de población que no presen- 
ta carencias físicas en la vivienda, pero en cuyos hogares existen más de tres dependientes por persona activa y jefes de familia con cuatro años o menos de instrucción escolar. Es decir, se han logrado superar las carencias en las viviendas y acceso a servicios básicos, pero los bajos niveles educacionales de los jefes de familia y la elevada tasa de dependencia, mantienen la condición de vulnerabilidad de estos hogares.

- Población en condición de pobreza reciente: En este grupo de población se observan carencias físicas en la vivienda y en el acceso a servicios básicos, pero no se encuentran en situación de vulnerabilidad. En este caso, existe una condición más favorable, y de más corto plazo, para la superación de la pobreza, relacionada, principalmente, con un mejoramiento de las condiciones físicas de las viviendas y acceso a servicios básicos.

- Población no pobre: Grupo de población que no presenta carencias físicas en las viviendas y cuyos hogares no se encuentran en condición de vulnerabilidad. No constituyen un grupo social prioritario para los programas de gobierno, aun cuando, y dependiendo de crisis económicas coyunturales, pueden experimentar un retroceso en su condición social y económica.

Finalmente, los datos de los Censos de Población de 1992 y 2002 fueron representados a nivel de distrito y zona censal, tanto en la situación actual de alguna variable como también su evolución en el tiempo. La información fue procesada en el programa REDATAM-G4 (CELADE, 2001).

\section{Resultados}

\section{Desarrollo urbano reciente de la ciudad de Los Ángeles}

En la ciudad de Los Ángeles pueden ser observados dos procesos de crecimiento urbano; el primero, marcado por una mayor densificación de las áreas urbanas ya consolidadas, y el segundo, un crecimiento en extensión a cada vez mayores distancias del centro histórico. En este sentido, algunos estudios confirman el aumento de suelos con uso residencial, industrial, equipamiento y zonas de expansión y a la vez, una disminución de las tierras agrícolas situadas en la periferia urbana (Azócar et al., 2007; Henríquez et al., 2006; Aguayo et al., 2007). Este último tipo de crecimiento, denominado en extensión, continuo y no continuo, es considerado inadecuado por los planificadores urbanos locales, debido, principalmente, al aumento de los costos que representa la provisión de servicios, equipamientos e infraestructura a mayores distancias de la ciudad, especialmente para usos residenciales (Figuras $\mathrm{N}^{\circ} 3$ y $\mathrm{N}^{\circ} 4$ ). Junto con lo anterior, se ha consolidado una morfología urbana que adopta la forma de anillos concéntricos y de ejes, asociados a sectores específicos de la ciudad, usos del suelo, zonas socioeconómicas, densidades de población y determinados tipos de paisajes, rasgo característico de las ciudades latinoamericanas (De Mattos, 2002). La ciudad presenta una estructura monocéntrica concentrando, principalmente en un primer anillo cercano al centro, los servicios y el sector terciario, con usos mixtos del suelo, compuestos básicamente por la presencia de servicios, comercio y uso residencial. Hacia el sur y norponiente de esta primera zona, el uso predominante es residencial, junto con la localización de algunos servicios específicos. El uso industrial se presenta a través de la Ruta 5 Sur, tanto en los accesos norte como sur, con numerosos talleres, bodegas de almacenamiento, distribución y agroindustrias. Desde este punto de vista, es importante señalar que las vías de transporte y comunicación, han representado un elemento que ha reordenado el espacio urbano-rural, incentivando, como factor de accesibilidad, los cambios de uso del suelo y el surgimiento de nuevos núcleos industriales, particularmente a los largo de las vías estructurantes y bypass.

En general, el proceso de urbanización ha ido a la par con un crecimiento espacial de la ciudad prácticamente incontrolado, provocando transformaciones en su estructura socioespacial y generando polarización y segregación del espacio urbano. Buenos ejemplos son los condominios y parcelas de agrado localizados fuera de los límites urba- 
Figura $\mathrm{N}^{\circ} 3$

PATRÓN DE CRECIMIENTO CONTINUO 1995-2006

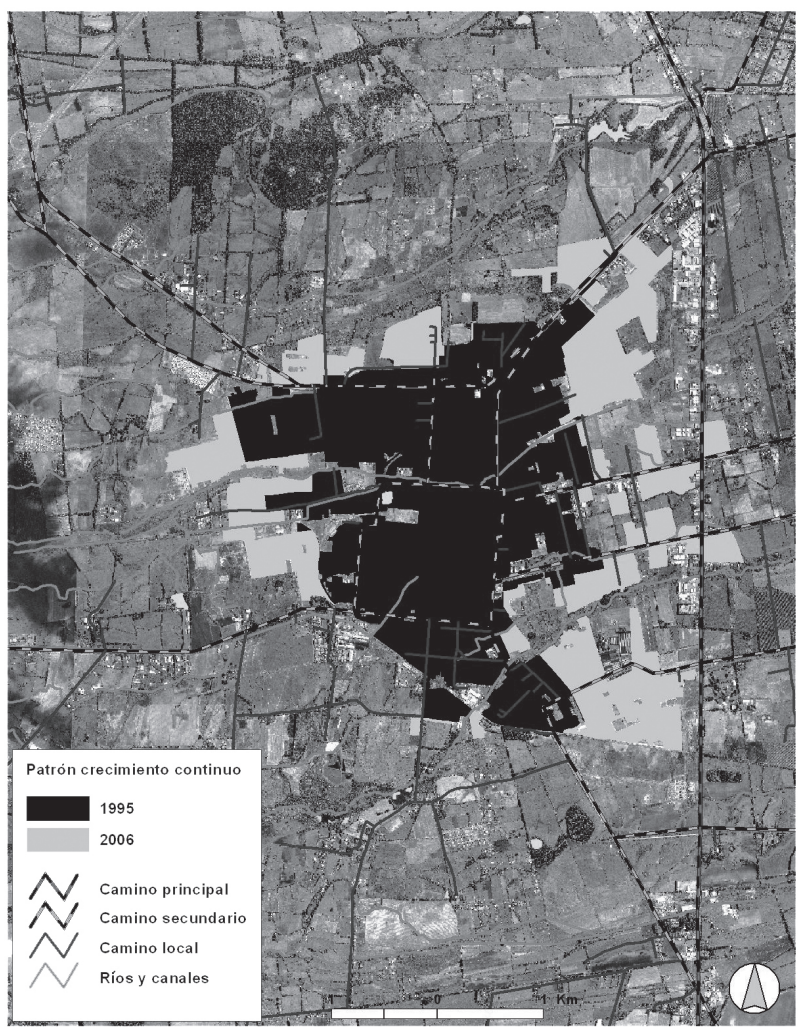

Fuente: Elaboración propia sobre la base de imágenes satelitales IKONOS (2006).

Figura $\mathrm{N}^{\circ} 4$

PATRÓN DE CRECIMIENTO NO CONTINUO 1995-2006

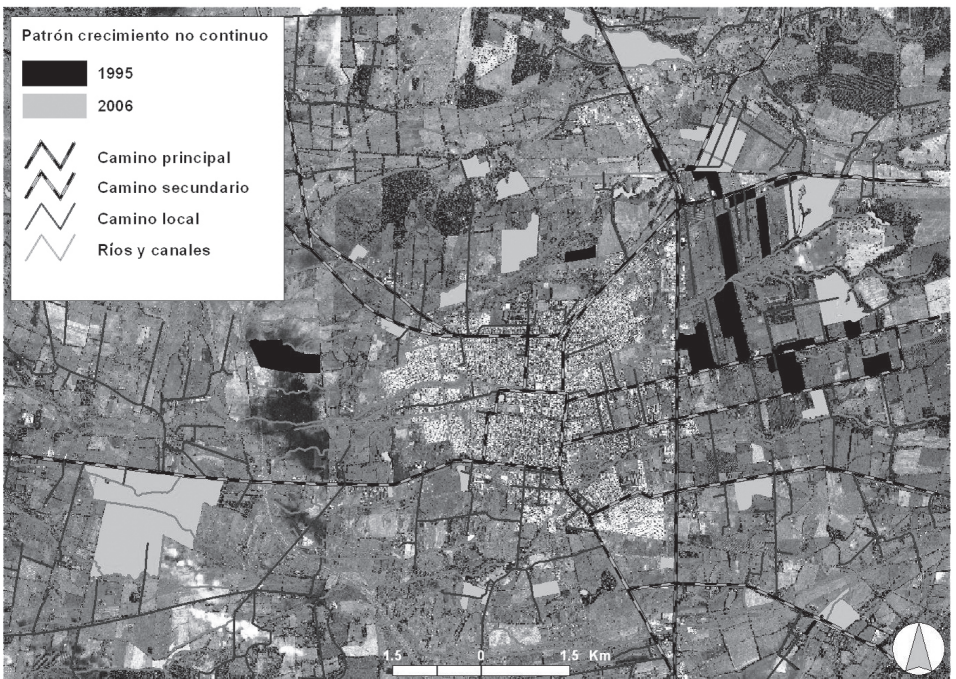

Fuente: Elaboración propia sobre la base de imágenes satelitales IKONOS (2006). 
nos, el surgimiento de grandes centros comerciales y equipamientos para grupos de altos ingresos y los nuevos ejes industriales asociados a las principales vías de transporte. De este modo es posible observar una particular configuración del espacio urbano: proyectos inmobiliarios destinados a grupos de ingresos medios altos en el sector poniente y oriente de la ciudad, y viviendas sociales y una mayor densidad urbana en la ocupación del suelo, para uso residencial, en áreas consolidadas y más próximas al centro histórico, especialmente en la zona sur y oeste.

Evidentemente, existe una separación física de los grupos sociales, expresada, además, en desiguales configuraciones y vulnerabilidades sociodemográficas. Para los planificadores locales, lo anterior ha sido fruto, entre otros factores, de la liberalización del uso del suelo en la década del ochenta, período en el cual la estatal Corporación de la Vivienda (CORVI), desarrolló importantes proyectos de viviendas sociales en las áreas antes mencionadas. Un buen ejemplo, ha sido el rápido crecimiento del barrio Paillihue, localizado al sur del centro histórico de la ciudad. Dicha zona, antaño eminentemente agrícola, pasó de una población estimada de mil personas, en la década del ochenta, a 23 mil habitantes en la actualidad. Para el asesor urbano de Los Ángeles ${ }^{6}$, la ciudad habría alcanzado un nivel más equilibrado o de menor intensidad en

\footnotetext{
6 Entrevista al Sr. Mauricio Carrasco (2006), asesor urbano de la llustre Municipalidad de Los Ángeles, Arquitecto Plan Regulador 2006.
}

Figura $\mathrm{N}^{0} 5$

DESARROLLO URBANO RECIENTE (1995-2007): SANTA MARÍA DE LOS ÁNGELES, DISTRITOS CENSALES AVENIDA MAIPÚ, ESTACIÓN ARRAYÁN Y HUMÁN

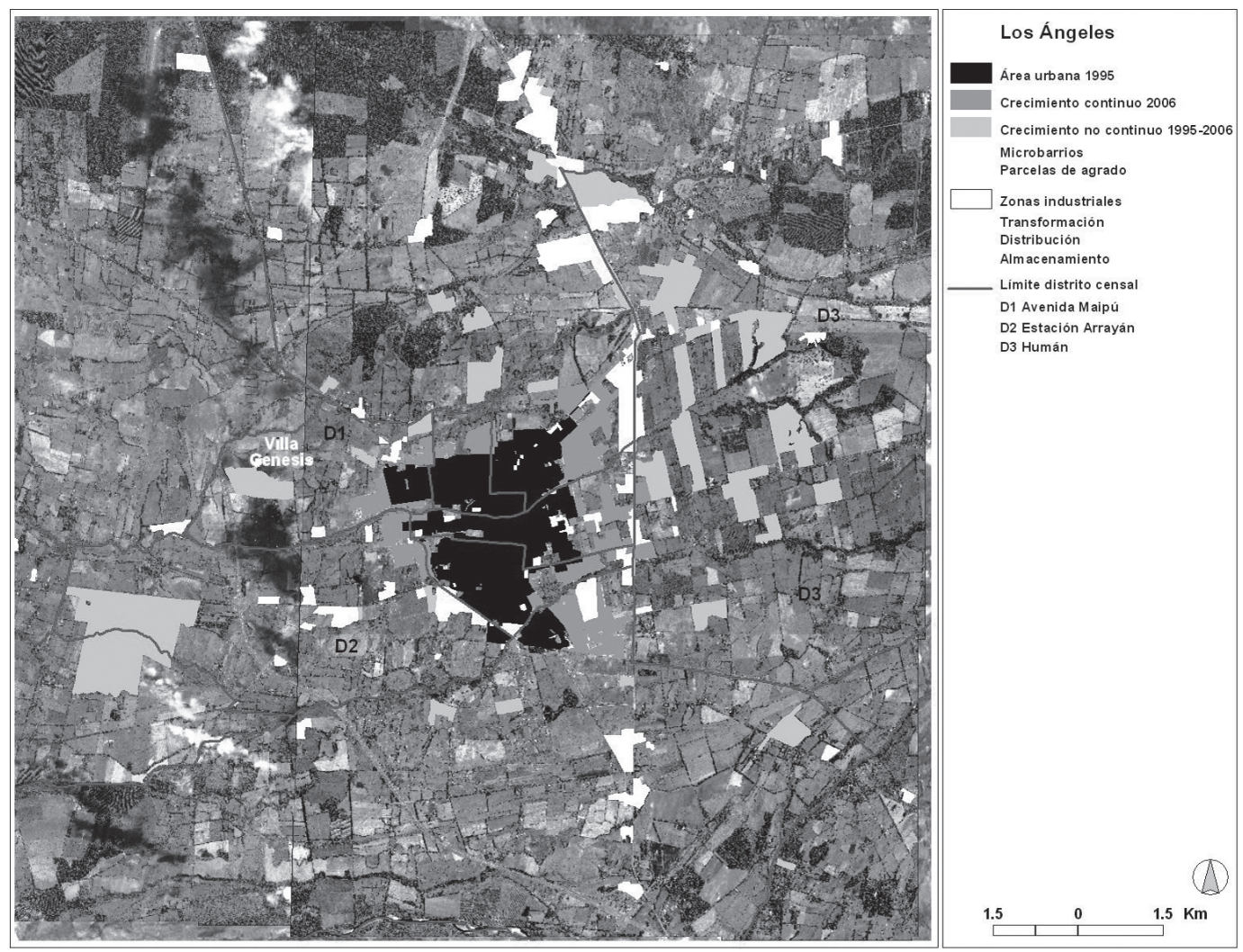

Fuente: Elaboración propia sobre la base de imágenes satelitales IKONOS (2006) e información de loteos del Servicio Agrícola y Ganadero (SAG, 2006). 
su proceso de expansión, situación que impediría un crecimiento similar al observado en las décadas pasadas. Para este funcionario, la ciudad ya consumió el suelo que necesitaba, especialmente en la periferia urbana, y en la actualidad, lo que debiera ocurrir es una mayor densificación de las áreas más centrales que durante el proceso de crecimiento quedaron sin uso o prácticamente vacías. En otras palabras, se estaría volviendo en términos de desarrollo urbano, hacia áreas más centrales en desmedro de un crecimiento en extensión a mayores distancias.

No obstante lo anterior, existen evidencias del surgimiento de importantes proyectos inmobiliarios, constituidos por parcelas de superficies de $5.000 \mathrm{~m}^{2}$ en la periferia urbana, especialmente hacia el oriente, como también de otros proyectos similares y de ocupaciones irregulares hacia el poniente, próximas al bypass de la Ruta 5 Sur (Figura $\mathrm{N}^{\circ} 5$ ).

\section{Los distritos censales del área de estudio}

El distrito Humán se ubica al oriente de la ciudad de Los Ángeles, en un sector que antiguamente era agrícola. El poblamiento urbano actual se inició principalmente a partir de 1985, año en que se promulgó el Decreto Ley 3.516, normativa que permitió la subdivisión del suelo rural y el surgimiento de las denominadas parcelas de agrado y microbarrios en la zona (Figura $N^{\circ} 6$ ). Este tipo de proyectos, forjó una dinámica urbana inédita hasta ese entonces, con la cons-

Figura $\mathrm{N}^{\circ} 6$

ESTRUCTURA PROYECTO DE LOTEO DEL DISTRITO CENSAL HUMÁN Y VIVIENDAS SOCIALES BARRIO PAILLIHUE, SANTA MARÍA DE LOS ÁNGELES (2006)
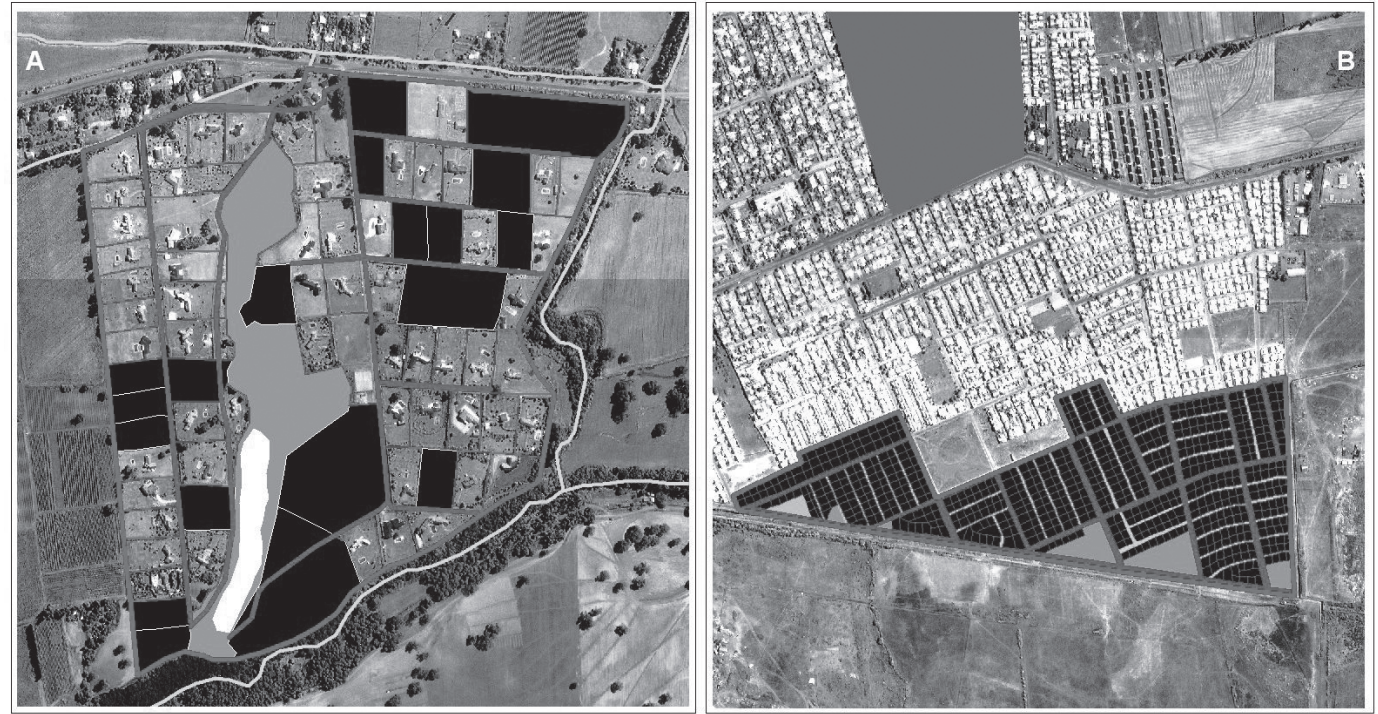

\begin{tabular}{|c|c|c|c|c|}
\hline \multicolumn{5}{|c|}{ A Parcelación distrito Humán } \\
\hline & \multicolumn{2}{|c|}{ Limite proyecto parcelación } & \multicolumn{2}{|c|}{ Lotes $\sin$ desarrollo } \\
\hline & \multicolumn{2}{|c|}{ División lotes o parcelas } & & Vegetación nativa \\
\hline & $\begin{array}{l}\text { Vialidad intern } \\
\text { Esteros y cana }\end{array}$ & & Embalse & \\
\hline & Superficie (ha) & Número Lotes & Densidad (Viv/ha) & Densidad ( $\mathrm{Hab} / \mathrm{ha}$ ) \\
\hline A & 37,9 & 64 & 0.6 & 6,8 \\
\hline B & 13,9 & 719 & 51,7 & 206,9 \\
\hline
\end{tabular}

B Proyecto viviendas sociales barrio Paillihue

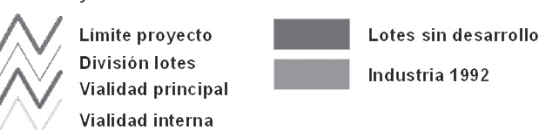

Vialidad interna

Fuente: Elaboración propia sobre la base de imágenes satelitales IKONOS (2006) e información de loteos del Servicio Agrícola y Ganadero (SAG, 2006). 
trucción de infraestructura vial y equipamiento urbano asociado. Este distrito se caracteriza, entre otros aspectos, por poseer suelos agrícolas de alta calidad, con disponibilidad de riego, escasa densidad poblacional y un gran valor paisajístico de su entorno.

Al poniente del centro histórico de Los Ángeles, se localizan los distritos censales Estación Arrayán y Maipú. Estas áreas antes de su urbanización, eran inundables y consideradas el patio trasero de la ciudad. A partir del año 1985, aproximadamente, y al igual que el distrito antes mencionado, comenzó un importante desarrollo de proyectos habitacionales, con subsidios del Estado de 300, 500 y 1.000 viviendas. El aumento de población y de actividades residenciales generó impactos en la dinámica urbana, con un considerable incremento del parque de transporte público y privado. Paralelamente, creció la sensación de inseguridad y la delincuencia, observándose una suerte de estigmatización de estos sectores habitacionales. Actualmente, estas zonas urbanas presentan carencias de equipamiento y de servicios básicos, junto con una alta densidad de población. Si bien, en su origen, estos sectores estaban alejados del centro histórico de Los Ángeles, más bien en una zona de contacto con las áreas rurales circundantes, con la construcción del nuevo bypass en la Ruta 5 Sur, así como también de nuevo equipamiento y servicios urbanos, se inició, a partir de la década del ochenta, un lento proceso de consolidación que, finalmente, daría origen a una nueva ciudad satélite.

Otra importante característica del área de estudio es el uso del suelo, que corresponde a una mezcla de usos propiamente
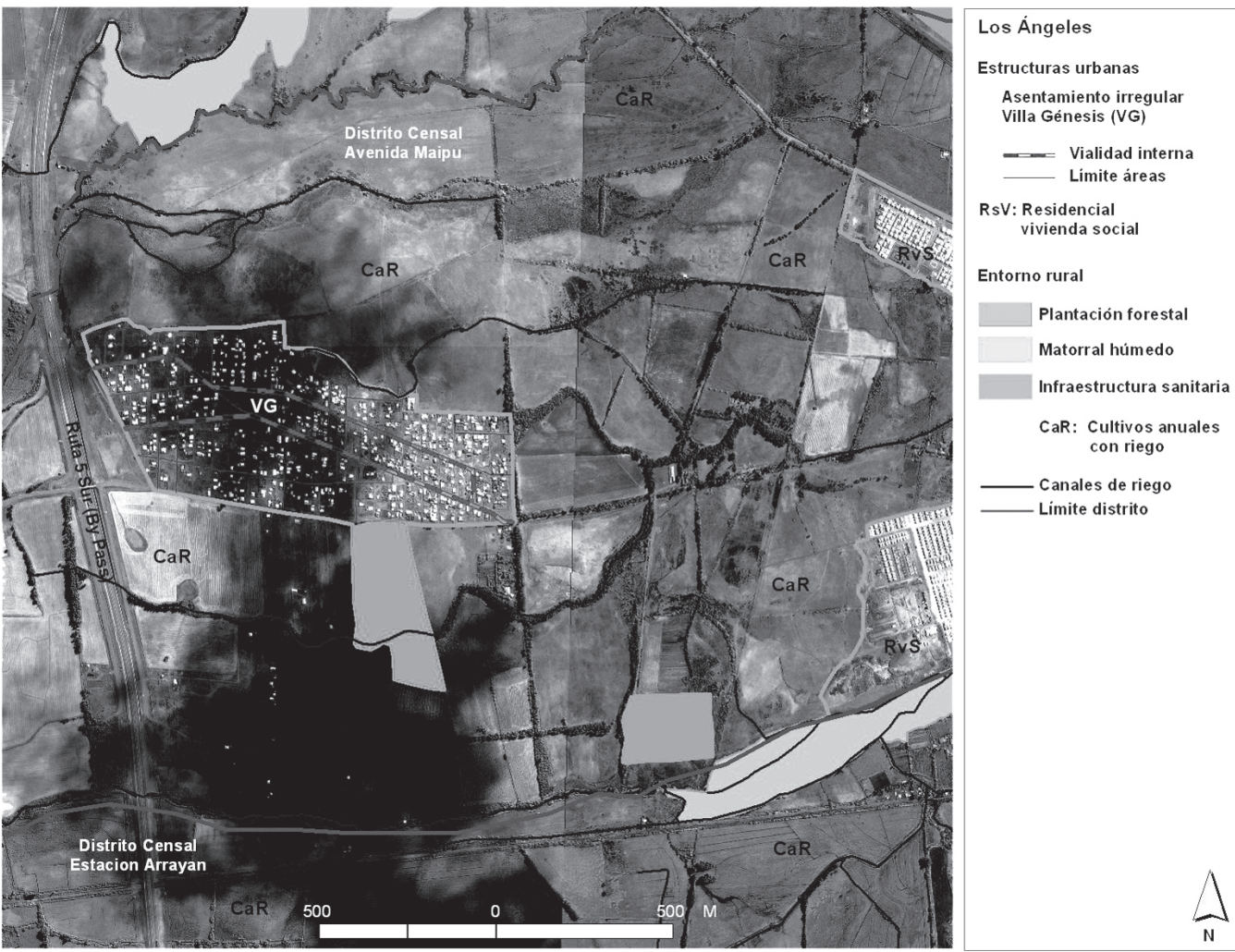

Fuente: Elaboración propia sobre la base de imágenes satelitales IKONOS (2006) e información de la Ilustre Municipalidad de Los Ángeles 2006 (Carrasco, 2006). 
urbanos, como es el caso del uso residencial en el distrito Maipú, y otros más vinculados a actividades agropecuarias, especialmente en los distritos Humán y Estación Arrayán. Lo anterior revela la dinámica del desarrollo urbano más reciente de la ciudad en áreas de borde urbano/rural, situación que ha significado, entre otros efectos, la pérdida de suelos agrícolas de alta calidad y productividad ${ }^{7}$, como también la alteración o pérdida de zonas de humedales, esteros y ríos. Junto a ello ha sucedido un rápido crecimiento y el surgimiento de ocupaciones residenciales irregulares, como la denominada Villa Génesis, ubicada al poniente de Los Ángeles (Figura $\mathrm{N}^{\circ} 7$ ).

\section{Los factores demográficos}

La tendencia general observada en los distritos analizados ha sido un importante aumento de su población urbana entre los Censos de 1992 y 2002, junto con una significativa disminución de su población rural, particularmente en el distrito Avenida Maipú. La población total de los tres distritos aumentó en este período de 10.794 a 33.432 habitantes, con una tasa de crecimiento anual de $12 \%$ y una variación de la población de 209,7\% (Cuadro $N^{\circ} 1$ ). Lo an-

7 Respecto a la pérdida de suelos agrícolas, Soto y Ulloa (1997) señalan que entre el 20 y $25 \%$ del terreno normado por el Plan Regulador Comunal de Los Ángeles del año 1989 fue proyectado sobre suelos Clase Ir, IIr y IIIr de capacidad de uso. terior, entre otros aspectos, se ha traducido en una mayor densidad de población y de ocupación del suelo urbano, especialmente en el distrito Avenida Maipú, zona en la cual se han desarrollado la mayor parte de los proyectos de viviendas sociales de la comuna y ciudad de Los Ángeles.

Respecto de los procesos demográficos, los datos analizados permiten afirmar que los distritos del área de estudio presentan un proceso de envejecimiento de su población, producto del descenso de la fecundidad y del incremento, pronunciado y sostenido, de la población adulta mayor (Cuadro $N^{\circ} 2$ ). Un análisis más detallado, según grupos quinquenales de edad y sexo, indica una importante disminución relativa, entre ambos períodos, de los menores de 4 años; la disminución, más o menos constante, de la población hasta el grupo etario de entre 30 y 34 años, y el aumento significativo de los individuos entre los 40 y 59 años, con un valor máximo de $71,4 \%$ para el grupo de entre 70 y 74 años. Desde un punto de vista espacial, es posible identificar ciertos patrones asociados a determinados grupos de edades y zonas urbanas y rurales. Por ejemplo, Avenida Maipú presenta la mayor disminución de la población menor de 15 años entre los años 1992 y 2002 (-14,9\%), como también el mayor aumento relativo de los mayores de 64 años $(89,5 \%)$. A su vez, en Humán se observa la menor disminución de población joven, pero, a la vez, un importante incremento de los mayores de 64 años (Cuadro $\mathrm{N}^{\circ} 3$ ).

Cuadro $\mathrm{N}^{\circ} 1$

TASA DE CRECIMIENTO DE LA POBLACIÓN Y VARIACIÓN INTERCENSAL SEGÚN DISTRITO CENSAL

\begin{tabular}{|l|r|c|c|c|}
\hline Distrito Censal & $\begin{array}{c}\text { Población } \\
1992\end{array}$ & $\begin{array}{c}\text { Población } \\
2002\end{array}$ & $\begin{array}{c}\text { Tasa promedio } \\
\text { crecimiento anual (\%) }\end{array}$ & $\begin{array}{c}\text { Variación intercensal } \\
\text { promedio (\%) }\end{array}$ \\
\hline Humán & 3.941 & 4.525 & 1,4 & 14,8 \\
Estación Arrayán & 6.695 & 9.179 & 3,2 & 37,1 \\
Avenida Maipú & 158 & 19.728 & 62,1 & $12.386,1$ \\
Total & 10.794 & 33.432 & 12,0 & 209,7 \\
\hline
\end{tabular}

Fuente: Elaboración propia. Instituto Nacional de Estadísticas (INE), Censos de Población y Vivienda años 1992 y 2002. Información procesada en Redatam G-4. 
Respecto de la modificación de la estructura de edades, se puede identificar el surgimiento de una nueva categoría social de riesgo, los adultos mayores, situación que se refleja en el aumento del índice de envejecimiento de la población entre ambos Censos (Cuadro $\mathrm{N}^{\circ} 4$ ). Este proceso, además de plantear enormes desafíos en términos de políticas públicas y, especialmente, en materia de distribución generacional del gasto social, también representa, por lo menos en la fase en que se reduce significativamente la población más joven, una ventana de oportunidades para el desarrollo económi-

Cuadro $\mathrm{N}^{\circ} 2$

VARIACIÓN DE LA POBLACIÓN EN LOS

DISTRITOS CENSALES DEL ÁREA DE ESTUDIO

SEGÚN GRUPOS ETARIOS PRINCIPALES, CENSOS DE 1992 Y 2002

\begin{tabular}{|c|r|r|c|}
\hline $\begin{array}{c}\text { Grupos etarios } \\
\text { (años) }\end{array}$ & $\begin{array}{c}1992 \\
(\%)\end{array}$ & $\begin{array}{c}2002 \\
(\%)\end{array}$ & $\begin{array}{c}\text { Tasa de } \\
\text { cambio (\%) }\end{array}$ \\
\hline$<15$ & 34,3 & 30,5 & $-11,1$ \\
$15-64$ & 62,5 & 65,5 & 4,8 \\
65 y más & 3,2 & 4,0 & 25,0 \\
\hline
\end{tabular}

Fuente: Elaboración propia. Instituto Nacional de Estadísticas (INE), Censos de Población y Vivienda años 1992 y 2002. Información procesada en Redatam G-4. co, debido a que disminuyen los dependientes jóvenes (Cuadro No 5) sin que todavía se incrementen, significativamente, los dependientes mayores (Duryea \& Székely, 1998; Magno de Carvalho, 1998).

Otro importante indicador que refleja el proceso de envejecimiento de la población es la Tasa Global de Fecundidad (TGF) ${ }^{9}$. En Chile, la TGF pasó de 5 hijos por mujer, en 1955, a 2,4 en el año 2002. En los distritos del área de estudio, entre los censos de 1992 y 2002, se produce una disminución de la TGF, pasando de 2,1 hijos en 1992 a

\section{Cuadro $\mathrm{N}^{\circ} 3$ \\ VALORES DE LAS TASAS DE CAMBIO SEGÚN GRUPOS PRINCIPALES DE EDAD Y DISTRITO CENSAL, CENSOS DE 1992 Y 2002}

\begin{tabular}{|l|c|c|c|}
\hline Distrito Censal & \multicolumn{2}{|c|}{$\begin{array}{c}\text { Tasa de cambio según } \\
\text { grupo etario } \\
1992-2002(\%)\end{array}$} \\
\hline & $<15$ & $15-64$ & 65 y más \\
Humán & $-6,8$ & $-0,2$ & 52,3 \\
Estación Arrayán & -12 & 5,5 & 34,6 \\
Avenida Maipú & $-14,9$ & 5,8 & 89,5 \\
\hline
\end{tabular}

Fuente: Elaboración propia. Instituto Nacional de Estadísticas (INE), Censos de Población y Vivienda años 1992 y 2002. Información procesada en Redatam G-4.

ÍNDICE DE ENVEJECIMIENTO8 Y TASA DE CAMBIO SEGÚN DISTRITO CENSAL, CENSOS DE 1992 Y 2002

\begin{tabular}{|l|c|c|c|}
\hline \multicolumn{1}{|c|}{ Distrito } & $\begin{array}{c}\text { Índice de } \\
\text { envejecimiento } \\
1992(\%)\end{array}$ & $\begin{array}{c}\text { Índice de } \\
\text { envejecimiento } \\
2002(\%)\end{array}$ & $\begin{array}{c}\text { Variación intercensal } \\
(\%)\end{array}$ \\
\hline Estación Arrayán & 7,0 & 10,8 & 54,3 \\
Humán & 14,0 & 22,8 & 62,9 \\
Avenida Maipú & 5,0 & 11,9 & 23,8 \\
\hline
\end{tabular}

Fuente: Elaboración propia sobre la base de los Censos de Población y Vivienda de los años 1992 y 2002. Información procesada en Redatam G-4.

\footnotetext{
8 Cociente entre la población de 65 años y más y la población de menores de 15 años de edad.
}

\footnotetext{
9 La Tasa Global de Fecundidad (TGF) es el número promedio de hijos que tendría una mujer de una co-
} 


\section{Cuadro $\mathrm{N}^{\circ} 5$}

ÍNDICE DE DEPENDENCIA DEMOGRÁFICA (IDP) ${ }^{10}$ Y TASA DE CAMBIO SEGÚN DISTRITO CENSAL, CENSOS DE 1992 Y 2002

\begin{tabular}{|l|c|c|c|c|c|c|c|}
\hline \multicolumn{1}{|c|}{ Distrito } & $\begin{array}{c}\text { Pob. } \\
0-14 \\
>65 \text { años } \\
(1992)\end{array}$ & $\begin{array}{c}\text { Pob. } \\
15-64 \text { años } \\
(1992)\end{array}$ & $\begin{array}{c}\text { IDP } \\
1992 \\
(\%)\end{array}$ & $\begin{array}{c}\text { Pob. } \\
0-14 \text { y } \\
65 \text { años } \\
(2002)\end{array}$ & $\begin{array}{c}\text { Pob. } \\
15-64 \text { años } \\
(2002)\end{array}$ & $\begin{array}{c}\text { IDP } \\
2002 \\
(\%)\end{array}$ & $\begin{array}{c}\text { Tasa } \\
\text { cambio } \\
\text { IDP }(\%)\end{array}$ \\
\hline Estación & & & & & & & \\
Arrayán & 2.560 & 4.135 & 62 & 3.203 & 5.976 & 54 & $-13,4$ \\
$\begin{array}{l}\text { Humán } \\
\text { Avenida }\end{array}$ & 1.433 & 2.508 & 57 & 1.661 & 2.864 & 58 & 1,5 \\
Maipú & 59 & 99 & 60 & 6.659 & 13.069 & 51 & $-14,5$ \\
Total & 4.052 & 6.742 & 60 & 11.523 & 21.909 & 53 & $-12,5$ \\
\hline
\end{tabular}

Fuente: Elaboración propia sobre la base de los Censos de Población y Vivienda de los años 1992 y 2002 (INE). Información procesada en Redatam G-4.

1,6 hijos por mujer el año 2002. La mayor disminución en el valor de este indicador, se observa en el distrito Avenida Maipú $(-52 \%)$, con valores de 3,2 hijos por mujer en 1992 y 1,5 hijos por mujer el año 2002.

\section{Los factores socioeconómicos}

Entre los Censos de 1992 y 2002 se aprecia un aumento de la fuerza de trabajo, especialmente en los distritos Avenida Maipú y Humán (Cuadro $N^{\circ} 6$ ), aspecto relacionado con el remodelamiento de la estructura etaria de la población, especialmente de los grupos más jóvenes, el sostenido aumento de los individuos en los grupos centrales de edades, particularmente a partir de los 35 años, y la disminución del índice de dependencia demográfico en dos de los tres distritos. Lo anterior pone de manifiesto el cambio en la relación de dependencia demográfica, con una disminución de la denominada infantilización de la dependencia demográfica y un lento, pero sostenido aumento de esta res-

horte hipotética de mujeres que durante su vida fértil tuviera sus hijos de acuerdo con las tasas de fecundidad por edad del período de estudio y no estuviera sometidas a riesgos de mortalidad desde el nacimiento hasta la finalización del período fértil.

${ }^{10}$ Cociente entre la población en edad pasiva (0-14 años de edad más la población de 64 años y más) con respecto a la población en edad considerada activa (15-59 años). pecto de los grupos de edad mayores. En relación con el empleo, en 1992 la población desocupada en los tres distritos del área de estudio representaba un $4,7 \%$ respecto al total de la fuerza laboral, con un valor mínimo de 2,1\% en Avenida Maipú y un valor máximo de desocupación de un 5\% en Estación Arrayán. Los datos del Censo del 2002 muestran, como tendencia más estructural, un aumento del desempleo para todos los distritos analizados (Cuadro $\left.\mathrm{N}^{0} 7\right)^{11}$.

Las actividades económicas de la población, se relacionan con cuatro actividades principales: agricultura, comercio, industria y servicio doméstico. En este sentido, un rasgo distintivo en las últimas décadas ha sido el importante auge de la actividad industrial y agroindustrial, principalmente forestal, y el mantenimiento de una agricultura de riego intensiva, ambas con efectos económicos multiplicadores importantes, especialmente

\footnotetext{
11 Al respecto, cabe señalar que, en estricto rigor, ambos períodos censales no son comparables ya que responden a situaciones económicas coyunturales diferentes que, en buena medida, explican los niveles de desempleo observados en esos años. Es así como en 1992 el Producto Interno Bruto Nacional (PIB) tuvo un crecimiento de $12 \%$ y el año 2002 de solo un $2,2 \%$, aspecto que indudablemente influye en la generación de nuevos puestos de trabajo. Sin embargo, la comparación entre ambos Censos permite obtener una mirada del comportamiento de este indicador a más largo plazo.
} 
Cuadro $N^{\circ} 6$

POBLACIÓN ECONÓMICAMENTE ACTIVA (PEA), ÍNDICE DE DEPENDENCIA DEMOGRÁFICO (IDP) Y TASA DE CAMBIO, CENSOS DE 1992 Y 2002

\begin{tabular}{|l|r|r|r|r|r|r|r|r|r|}
\hline \multicolumn{1}{|c|}{ Distrito Censal } & $\begin{array}{r}\text { Pob. } \\
1992\end{array}$ & $\begin{array}{c}\text { PEA } \\
1992\end{array}$ & $\%$ & $\begin{array}{r}\text { IDP } \\
(\%)\end{array}$ & $\begin{array}{r}\text { Pob. } \\
2002\end{array}$ & $\begin{array}{r}\text { PEA } \\
2002\end{array}$ & $\%$ & $\begin{array}{r}\text { IDP } \\
(\%)\end{array}$ & $\begin{array}{c}\text { Variación } \\
\text { intercensal } \\
\text { PEA }(\%)\end{array}$ \\
\hline Estación Arrayán & 6.695 & 2.411 & 36,0 & 62 & 9.179 & 3.507 & 38,2 & 54 & 6,1 \\
Humán & 3.941 & 1.378 & 35,0 & 57 & 4.525 & 1.783 & 39,4 & 58 & 12,6 \\
Avenida Maipú & 158 & 48 & 30,4 & 60 & 19.728 & 7.732 & 39,2 & 51 & 28,9 \\
Total & 10.794 & 3.837 & 35,5 & 60 & 33.432 & 13.022 & 39,0 & 53 & 9,9 \\
\hline
\end{tabular}

Fuente: Elaboración propia sobre la base del Censo de Población y Vivienda de 1992 y 2002 (INE). Información procesada en Redatam G-4.

Cuadro $\mathrm{N}^{\circ} 7$

POBLACIÓN ECONÓMICAMENTE ACTIVA (PEA), DESOCUPACIÓN Y TASA DE CAMBIO, CENSOS DE 1992 Y 2002

\begin{tabular}{|l|r|c|r|r|r|r|c|}
\hline Distrito Censal & $\begin{array}{r}\text { PEA } \\
1992\end{array}$ & $\begin{array}{c}\text { PEA } \\
\text { desocupada }\end{array}$ & $\%$ & $\begin{array}{c}\text { PEA } \\
2002\end{array}$ & $\begin{array}{c}\text { PEA } \\
\text { desocupada }\end{array}$ & $\%$ & $\begin{array}{c}\text { Variación } \\
\text { intercensal } \\
\text { PEA (\%) }\end{array}$ \\
\hline Estación Arrayán & 2.411 & 120 & 5,0 & 3.507 & 344 & 9,8 & 96,0 \\
Humán & 1.378 & 60 & 4,4 & 1.783 & 139 & 7,8 & 77,3 \\
Avenida Maipú & 48 & 1 & 2,1 & 7.732 & 963 & 12,5 & 495,2 \\
Total & 3.837 & 181 & 4,7 & 13.022 & 1.446 & 11,1 & 136,2 \\
\hline
\end{tabular}

Fuente: Elaboración propia sobre la base del Censo de Población y Vivienda de 1992 y 2002 (INE). Información procesada en Redatam G-4.

como oferta de trabajo y crecientes demandas de bienes y servicios asociados. La comparación de la fuerza de trabajo, ocupada por rama de actividad económica, entre ambos Censos muestra una notoria caída de la población ocupada en la agricultura; una participación más o menos constante de la actividad industrial, en torno al $15 \%$, y aumentos significativos del comercio $(21,1 \%)$ y construcción (10,2\%). A su vez, emergen con fuerza otros sectores económicos que en 1992, tenían una menor participación en la estructura de ocupación, especialmente los servicios, actividades inmobiliarias y financieras. Lo anterior, y como tendencia más general, también puede ser observado a nivel de distrito censal, manteniéndose la agricul- tura, como principal fuente generadora de trabajo, solo en el distrito Humán, pero disminuyendo su participación respecto del año 1992 (Cuadro No 8).

La interpretación de los cambios en la estructura de ocupación de la población estaría asociada a los siguientes aspectos: i) El importante impulso de la actividad forestal silvícola e industrial en la provincia de Biobío y comuna de Los Ángeles; ii) El efecto de las inversiones y proyectos del sector industrial y agroindustrial sobre el comercio, construcción, servicios, transporte, actividades financieras e inmobiliarias, y iii) El notable crecimiento urbano de la ciudad en las últimas décadas. 
Cuadro $N^{\circ} 8$

ACTIVIDADES ECONÓMICAS DE LA POBLACIÓN Y TASA DE CAMBIO SEGÚN DISTRITO CENSAL, CENSOS DE 1992 Y 2002

\begin{tabular}{|l|r|r|r|r|r|r|r|r|r|}
\hline \multirow{2}{*}{$\begin{array}{c}\text { Sector } \\
\text { Económico }\end{array}$} & \multicolumn{2}{|c|}{ Estación Arrayán } & \multicolumn{3}{c|}{ Humán } & \multicolumn{3}{c|}{ AvenidaMaipú } \\
\cline { 2 - 9 } & $\begin{array}{r}1992 \\
(\%)\end{array}$ & $\begin{array}{r}2002 \\
(\%)\end{array}$ & $\begin{array}{r}\text { Var. } \\
(\%)\end{array}$ & $\begin{array}{r}1992 \\
(\%)\end{array}$ & $\begin{array}{r}2002 \\
(\%)\end{array}$ & $\begin{array}{r}\text { Var. } \\
(\%)\end{array}$ & $\begin{array}{r}1992 \\
(\%)\end{array}$ & $\begin{array}{r}2002 \\
(\%)\end{array}$ & $\begin{array}{r}\text { Var. } \\
(\%)\end{array}$ \\
\hline Agricultura & 12,2 & 7,6 & $-37,7$ & 50,9 & 29,0 & $-43,0$ & 29,0 & 5,5 & $-81,0$ \\
Pesca & 0,1 & 0,1 & 0 & 0,2 & 0 & & 0 & 0,4 & \\
Minería & 0,1 & 0,1 & 0 & 0,1 & 0,3 & 200,0 & 0,3 & 0,2 & $-33,3$ \\
Industria & 18,9 & 15,7 & $-16,9$ & 9,2 & 11,2 & 21,7 & 11,2 & 16,1 & 43,8 \\
Elect- agua y gas & 0,6 & 0,8 & 33,3 & 0,6 & 0,8 & 33,3 & 0,8 & 0,8 & 0 \\
Construcción & 6,8 & 6,9 & 1,5 & 3,8 & 6,0 & 57,9 & 6,0 & 12,6 & 110,0 \\
Comercio & 21,1 & 21 & $-0,5$ & 7,8 & 12,2 & 56,4 & 12,2 & 23,1 & 89,3 \\
Hot. y restaurant. & 1,6 & 2,4 & 50 & 1,0 & 1,5 & 50,0 & 1,5 & 2,4 & 60,0 \\
Transporte & 8,5 & 9,0 & 5,9 & 5,4 & 4,7 & $-13,0$ & 4,7 & 8,0 & 70,2 \\
Act. Financieras & 1,1 & 1,9 & 72,7 & 0,3 & 1,0 & 233,3 & 1,0 & 1,1 & 10,0 \\
Act. Inmobiliarias & 3,4 & 7,6 & 123,5 & 1,5 & 7,9 & 426,7 & 7,9 & 6,7 & $-15,2$ \\
Adm. Pública & 6,6 & 4,4 & $-33,3$ & 2,3 & 1,5 & $-34,8$ & 1,5 & 2,0 & 33,3 \\
Enseñanza & 6,5 & 8,2 & 26,2 & 3,5 & 5,1 & 45,7 & 5,1 & 4,5 & $-11,8$ \\
Salud & 4,7 & 6,4 & 36,2 & 1,7 & 4,3 & 152,9 & 4,3 & 3,3 & $-23,3$ \\
Servicios & 1,4 & 3,6 & 157,1 & 1,2 & 3,3 & 175,0 & 3,3 & 7,3 & 121,2 \\
Hogar privado & 6,4 & 4,3 & $-32,8$ & 10,5 & 11,2 & 6,7 & 11,2 & 6,0 & $-46,4$ \\
Total & 100,0 & 100,0 & & 100,0 & 100,0 & & 100,0 & 100,0 & \\
\hline
\end{tabular}

Fuente: Elaboración propia sobre la base del Censo de Población y Vivienda de 1992 (INE). Información procesada en Redatam G-4.

\section{Pobreza y vulnerabilidad social}

En general, y de acuerdo a los tres tipos o situaciones de pobreza considerados en el análisis, se observa entre ambos períodos una significativa reducción de los hogares en dicha condición; es decir, la población pobre disminuyó de un valor promedio de $53,4 \%$ en 1992 a un $30 \%$ el año 2002 (Cuadro $\mathrm{N}^{\circ}$ 9). La tasa de cambio promedio es negativa $(-43,8 \%)$, con un mejor comportamiento en los distritos Avenida Maipú $(-68,3 \%)$ y Humán $(-50 \%)$, aún cuando todos disminuyen de manera significativa los niveles de pobreza, especialmente la pobreza crítica.

Como se mencionó, entre ambos Censos se observa una importante disminución de la pobreza crítica (Cuadro $N^{0} 10$ ), con un valor promedio de 3,8\% para el año 2002, y una reducción de 18,9 puntos porcentuales respecto a 1992. Sin embargo, y pese a este positivo comportamiento, aún subsisten áreas con porcentajes elevados de pobreza crítica en los mismos distritos rurales identificados el año 1992 (5,2\% Humán y 4,0\% Avenida Maipú). Los mayores decrecimientos pueden ser observados en Avenida Maipú $(-94,2 \%)$ y Humán $(-87,8 \%)$.

Respecto de los hogares que no presentan carencias físicas o de habitabilidad en sus viviendas, aunque en los cuales existen más de tres dependientes por persona activa y jefes de familia con cuatro años o menos de instrucción escolar o bien analfabetos, es decir aquellos que constituyen la llamada pobreza inercial, también se distingue una disminución entre ambos períodos $(8,6 \%$, el 
Cuadro $\mathrm{N}^{\circ} 9$

HOGARES POBRES Y TASA DE CAMBIO SEGÚN DISTRITO CENSAL, CENSOS DE 1992 Y 2002

\begin{tabular}{|l|c|c|c|c|c|c|c|}
\hline \multicolumn{1}{|c|}{ Distrito } & $\begin{array}{c}\text { Total } \\
\text { hogares } \\
(1992)\end{array}$ & $\begin{array}{c}\text { Total } \\
\text { hogares } \\
\text { pobres }\end{array}$ & $\%$ & $\begin{array}{c}\text { Total } \\
\text { hogares } \\
(2002)\end{array}$ & $\begin{array}{c}\text { Total } \\
\text { hogares } \\
\text { pobres }\end{array}$ & $\%$ & $\begin{array}{c}\text { Variación } \\
\text { intercensal } \\
(\%)\end{array}$ \\
\hline Estación Arrayán & 2.072 & 922 & 44,5 & 2.515 & 738 & 29,3 & $-34,2$ \\
Humán & 917 & 662 & 72,2 & 1.208 & 436 & 36,1 & $-50,0$ \\
Avenida Maipú & 35 & 32 & 91,4 & 5.647 & 1.637 & 29,0 & $-68,3$ \\
Total & 3.024 & 1.616 & 53,4 & 9.370 & 2.811 & 30,0 & $-43,8$ \\
\hline
\end{tabular}

Fuente: Elaboración propia sobre la base del Censo de Población y Vivienda de 1992 y 2002 (INE). Información procesada en Redatam G-4.

Cuadro $N^{\circ} 10$

HOGARES EN CONDICIÓN DE POBREZA CRÍTICA Y TASA DE CAMBIO SEGÚN DISTRITO CENSAL, CENSOS DE 1992 Y 2002

\begin{tabular}{|l|r|c|c|c|c|c|c|}
\hline \multicolumn{1}{|c|}{ Distrito } & $\begin{array}{c}\text { Total } \\
\text { hogares } \\
(1992)\end{array}$ & $\begin{array}{c}\text { Total } \\
\text { hogares } \\
\text { críticos }\end{array}$ & $\%$ & $\begin{array}{c}\text { Total } \\
\text { hogares } \\
(2002)\end{array}$ & $\begin{array}{c}\text { Total } \\
\text { hogares } \\
\text { críticos }\end{array}$ & $\%$ & $\begin{array}{c}\text { Variación } \\
\text { intercensal } \\
(\%)\end{array}$ \\
\hline Estación Arrayán & 2.072 & 273 & 13,2 & 2.515 & 73 & 2,9 & $-78,0$ \\
Humán & 917 & 390 & 42,5 & 1.208 & 63 & 5,2 & $-87,8$ \\
Avenida Maipú & 35 & 24 & 68,6 & 5.647 & 224 & 4,0 & $-94,2$ \\
Total & 3.024 & 687 & 22,7 & 9.370 & 360 & 3,8 & $-83,3$ \\
\hline
\end{tabular}

Fuente: Elaboración propia sobre la base del Censo de Población y Vivienda de 1992 y 2002 (INE). Información procesada en Redatam G-4.

año 1992 y 6,8\%, el año 2002). En otras palabras, han logrado superar las carencias en las viviendas y acceso a servicios básico, pero aún mantienen su condición de vulnerabilidad y de riesgo social.

De este modo, los datos analizados muestran importantes avances en la superación de la pobreza en los distritos del área de estudio, especialmente de la pobreza crítica. Indudablemente, en los últimos diez años las políticas públicas han estado orientadas a mejorar y asegurar el acceso a servicios, equipamiento e infraestructura básica para los grupos sociales más vulnerables; incidiendo estas políticas de manera positiva en la superación de las carencias físicas o materiales de importantes segmentos de población. Sin embargo, no ha ocurrido lo mismo, o por lo menos con la misma intensidad, en la superación de las condiciones de vulnerabilidad y riesgo social de los hogares. Por otra parte, la superación de las condiciones de vulnerabilidad, medida a través de la categoría de pobreza inercial, en los últimos años, no ha sido suficiente para contrarrestar la pobreza en su sentido más amplio y quizás más importante; la formación de capital social a través de la educación.

\section{Segregación socioespacial y perfiles sociodemográficos}

Se observan claras diferencias en la ocupación del suelo urbano y en la dinámica que en los últimos años ha tenido el poblamiento y el comportamiento de las variables 
sociodemográficas en los distritos Estación Arrayán, Humán y Avenida Maipú. La concentración de viviendas sociales y de ocupaciones irregulares en Avenida Maipú, como es el caso de Villa Génesis en el extremo poniente de este distrito, contrasta con el auge inmobiliario de exclusivos proyectos residenciales y microbarrios para grupos sociales de ingresos medios y altos en Estación Arrayán y Humán. Desde un punto de vista sociodemográfico, es posible distinguir algunas diferencias entre los distritos analizados (Cuadro No 11): Avenida Maipú presenta la mayor tasa de crecimiento de su población, como también la mayor reducción o disminución relativa de los menores de 15 años y el mayor aumento de los mayores de 65 años. De igual manera, concentra el mayor número de jefes de familia sin estudios de ningún tipo, la menor cantidad de jefes de hogar con instrucción técnicouniversitaria, la mayor tasa de desempleo $(12,5 \%, 2002)$ e importantes niveles de pobreza crítica $(4 \%, 2002)$.

En el caso del distrito Humán, se han materializado importantes proyectos inmobiliarios para grupos sociales de ingresos medios y altos, observándose el denominado proceso de privatización del espacio urbano y la prolongación o extensión de la ciudad de Los Ángeles hacia las zonas rurales de dicha zona. Se trata de un área en proceso de transición o cambio, desde aquellos usos propiamente agrarios o rurales hacia actividades residenciales y agroindustriales. Desde esta perspectiva, es posible observar diferentes realidades sociodemográficas de sus residentes: por una parte, un sector de población de origen campesino, con asentamientos originados en el proceso de Reforma Agraria en la década de 1970, con altos niveles de pobreza $(36,1 \%$ en el año 2002) y pobreza crítica (5,2\% en 2002), como también bajos niveles de escolaridad de los jefes de familia (9\% sin instrucción) y el mayor porcentaje de población analfabeta del área de estudio (4,6\%).

Por otra parte, en este mismo distrito, y como consecuencia de los proyectos inmobiliarios, se ha generado un poblamiento más reciente, con individuos y/o grupos familiares que se han desplazado desde áreas urbanas más consolidadas y centrales de la ciudad de Los Ángeles. Este nuevo grupo de personas $y / u$ hogares ha influido sobre la estructura sociodemográfica de Humán, modificando el comportamiento de algunos indicadores entre los Censos de 1992 y 2002. Es así como este distrito presenta la mayor proporción de jefes de familia con estudios técnicos/universitarios (19\% en 2002) y los niveles más bajos de desempleo de toda el área de estudio (7,8\% el mismo año).

En otras palabras, dentro de una misma microzona geográfica, correspondiente al distrito censal de Humán, se aprecian realidades sociodemográficas bastante diferenciadas, concentrándose la pobreza y la pobreza crítica en bolsones o vestigios de un poblamiento agrario-rural de antigua data. La dinámica urbana que ha experimentado este distrito, también ha generado modificaciones en su orientación económico-productiva: cambios de uso del suelo de rural a urbano o agroindustrial, disminución de tierras agrícolas de riego, altamente productivas; sensible disminución, entre 1992 y 2002 , de la mano de obra empleada en la agricultura y un considerable aumento de la mano de obra ocupada en los sectores inmobiliario y financiero.

Un aspecto interesante en el desarrollo de los proyectos inmobiliarios en Humán, y a diferencia de lo ocurrido en otras ciudades del país, con dinámicas urbanas similares, ha sido el positivo aprovechamiento que los gestores privados han realizado de los recursos paisajísticos y/o ambientales que caracterizan las zonas rurales sobre las cuales se han emplazado. En otras palabras, han incorporado y puesto en valor en sus proyectos dichos recursos, principalmente la presencia de bosque nativo en quebradas y esteros, y de canales de riego y embalses. Ello ha potenciado el valor y atractivo de la oferta inmobiliaria residencial, principalmente hacia un segmento del mercado que busca, entre otras cosas, y como mecanismo o factor de diferenciación social, seguridad, belleza del entorno y privacidad, como también un claro factor de identidad social respecto de las condiciones o características agrarias y rurales que aún posee la zona.

Dicha impronta agraria que posee el distrito Humán y, en general la ciudad de Los 
Cuadro $\mathrm{N}^{\circ} 11$

PERFIL SOCIOECONÓMICO SEGÚN DISTRITO CENSAL, CENSOS DE 1992 Y 2002

\begin{tabular}{|c|c|c|c|}
\hline \multirow{2}{*}{ Variable } & \multicolumn{3}{|c|}{ Distrito } \\
\hline & $\begin{array}{l}\text { Estación } \\
\text { Arrayán }\end{array}$ & Humán & $\begin{array}{l}\text { Avenida } \\
\text { Maipú }\end{array}$ \\
\hline Población económicamente activa 2002 (\%) & 38,2 & 39,4 & 39,2 \\
\hline $\begin{array}{l}\text { Variación población } \\
\text { económicamente activa (\%) }\end{array}$ & 6,1 & 12,6 & 28,9 \\
\hline $\begin{array}{l}\text { Actividades económicas } \\
\text { predominantes } 2002\end{array}$ & $\begin{array}{l}\text { Comercio, } \\
\text { industria, } \\
\text { educación }\end{array}$ & $\begin{array}{l}\text { Agricultura } \\
\text { comercio, } \\
\text { industria, }\end{array}$ & $\begin{array}{l}\text { Comercio } \\
\text { industria, } \\
\text { construcción }\end{array}$ \\
\hline $\begin{array}{l}\text { Actividades económicas } \\
\text { emergentes } 2002\end{array}$ & $\begin{array}{l}\text { Servicios, } \\
\text { inmobiliaria, } \\
\text { financieras }\end{array}$ & $\begin{array}{l}\text { Inmobiliaria, } \\
\text { financiera, } \\
\text { salud }\end{array}$ & $\begin{array}{l}\text { Servicios, } \\
\text { comercio, } \\
\text { transporte }\end{array}$ \\
\hline $\begin{array}{l}\text { Tendencias actividades } \\
\text { económicas 1992-2002 }\end{array}$ & $\begin{array}{l}\text { - agricultura, } \\
+ \text { inmobiliaria } \\
\text { y servicio }\end{array}$ & $\begin{array}{l}\text { - agricultura } \\
+ \text { inmobiliaria } \\
\text { y financiera }\end{array}$ & $\begin{array}{l}\text { - agricultura } \\
\text { + servicio } \\
\text { y comercio }\end{array}$ \\
\hline Instrucción básica jefes defamilia 2002 (\%) & 60,4 & 63,4 & 66,8 \\
\hline Variación intercensal instrucción básica (\%) & 235,9 & 63,4 & 66,8 \\
\hline Jefes de familia sin estudios 2002 (\%) & 5,8 & 9,0 & 9,8 \\
\hline Variación jefes de familiasin estudios (\%) & 45,0 & $-4,3$ & $-14,0$ \\
\hline $\begin{array}{l}\text { Jefes familia con estudios } \\
\text { técnicos-universitarios } 2002(\%)\end{array}$ & 15,5 & 19,0 & 8,2 \\
\hline $\begin{array}{l}\text { Variación jefes familia estudios } \\
\text { técnicos-universitarios (\%) }\end{array}$ & 23,0 & 102,1 & 43,9 \\
\hline Población analfabeta 2002 (\%) & 2,4 & 4,6 & 4,2 \\
\hline $\begin{array}{l}\text { Variación intercensal población } \\
\text { analfabeta }(\%)\end{array}$ & $-71,1$ & -62 & $-72,4$ \\
\hline Tasa desempleo 2002 (\%) & 9,8 & 7,8 & 12,5 \\
\hline Variación tasa desempleo 1992-2002 (\%) & 96,0 & 77,3 & 495,2 \\
\hline Nivel de pobreza 2002 (\%) & 29,3 & 36,1 & 29,0 \\
\hline $\begin{array}{l}\text { Variación intercensal pobreza } \\
\text { 1992-2002 (\%) }\end{array}$ & $-34,2$ & $-50,0$ & $-68,3$ \\
\hline Pobreza crítica 2002 (\%) & 2,9 & 5,2 & 4,0 \\
\hline Variación intercensal pobreza crítica (\%) & $-78,0$ & $-87,8$ & $-94,2$ \\
\hline
\end{tabular}

Fuente: Elaboración propia. 
Ángeles, ha condicionado y, en buena medida, ha estructurado su desarrollo urbano más reciente. Un buen ejemplo son los canales de riego que atraviesan gran parte de este distrito, los cuales han actuado junto con la propiedad de la tierra, como verdaderos umbrales y/o separadores de usos y actividades económicas, como también de grupos sociales. La delimitación de microbarrios o condominios cerrados en Humán, como también los proyectos de loteo y parcelación de predios rústicos, en buena medida, se han estructurado y organizado, espacialmente, sobre la base de estos elementos territoriales, resabios de una actividad agraria, en otros tiempos, más intensiva y rentable.

Una lectura adicional, y no menos importante del desarrollo urbano-rural más reciente del distrito Humán y de los grupos sociales que en él habitan, ha sido la identificación de ciertas formas de integración socioeconómica de sus residentes, principalmente en el ámbito del empleo y de las oportunidades laborales, distintas a las tradicionales basadas en actividades agropecuarias. Lo anterior, como resultado de la demanda de mano de obra en la construcción de los proyectos inmobiliarios y de los requerimientos de servicio doméstico y de jardineros, por parte de los nuevos grupos sociales de altos ingresos. En este sentido, y de acuerdo a lo manifestado por algunos entrevistados, en sectores o áreas de origen campesino del distrito Humán existe una demanda de trabajo hacia la comunidad, originada por los residentes de los condominios o parcelas de agrado localizados en las cercanías.

Finalmente, cabe destacar que desde el punto de vista de la planificación urbana, los planes de los años 1981 y 1989 implementados en la ciudad de Los Ángeles se rigieron, básicamente, por una política de libre mercado, situación que favoreció un tipo de crecimiento inorgánico y segmentado y, a la vez, una suerte de apropiación por parte de los grupos más adinerados, los cuales, sobre la base de la oferta y demanda de suelo urbano le darían forma y contenido a la ciudad de Los Ángeles (Andaur y Pérez, 2007).

\section{Consideraciones finales}

A partir de los resultados obtenidos es posible afirmar que la diferenciación urbana y social observada en la ciudad de Los Ángeles está directamente relacionada con las características sociodemográficas de la población y con la aplicación de políticas de Estado, principalmente en materia de vivienda social. Estos perfiles demográficos, sociales y económicos de la población urbana, presentan un claro patrón de distribución espacial que, a la vez, es indicativo de diferentes vulnerabilidades y riesgos sociales, como también de procesos demográficos de largo aliento.

Los patrones espaciales de diferenciación social identificados pueden ser clasificados en dos escalas de análisis: por una parte, y pese a la importante reducción de la pobreza en las áreas urbanas, su distribución espacial no ha cambiado mucho en los últimos años, concentrándose en las mismas zonas geográficas de la ciudad y acentuándose la diferenciación social y espacial de la población, producto de las políticas de Estado y de las preferencias $y / u$ oportunidades de los gestores y consumidores de suelo urbano y rural. Por otro lado, también se observan áreas donde los grupos de mayores ingresos se han localizado en zonas que, anteriormente, habían sido ocupadas por los grupos de menores ingresos, generándose una reducción de las distancias físicas que les separaban, lo cual puede o no facilitar los procesos de interacción socioespacial.

En Los Ángeles, al igual que en otras ciudades de nuestro país, ha existido una mayor valoración de ciertas áreas urbanas y un proceso de exclusión de grupos sociales de bajos ingresos impedidos o limitados en sus posibilidades de localizarse en zonas urbanas de mayor plusvalía. De este modo, y debido al precio del suelo y los procesos especulativos asociados, a las intervenciones estatales en materia de construcción de viviendas sociales, los grupos de bajos ingresos se han localizado en aquellas áreas de la ciudad donde este precio pueda ser compatible con los recursos financieros disponibles, contribuyendo de esta manera a una mayor diferenciación y segmentación del es- 
pacio urbano. Lo anterior ha significado, por una parte, utilizar grandes extensiones de suelo en la periferia de la ciudad, en zonas rurales de alta productividad agrícola y, por otro lado, la subutilización de suelo urbano disponible al interior de la ciudad, debido a su elevado precio.

No obstante lo antes señalado, y pese al continuo crecimiento o extensión de la ciudad en las últimas décadas, principalmente de manera no continua y a mayores distancias del centro histórico, dicho proceso parece estar disminuyendo o, por lo menos en términos de gestión pública local, revirtiéndose hacia una gestión urbana que prioriza la renovación y/o revitalización de espacios más centrales. Sin embargo, la evaluación más detallada del proceso de crecimiento o decrecimiento futuro de este tipo de ciudades, y sus patrones de uso del suelo resultantes y procesos socioespaciales concomitantes deberá considerar, necesariamente, otra serie de variables y/o factores que directa o indirectamente lo condicionan, limitan o potencian.

Entre estos últimos, especial atención merecen el ritmo de las inversiones y su distribución territorial los cambios sociodemográficos de largo aliento y sus efectos sobre los asentamientos urbanos y zonas rurales, las tendencias observadas en la especialización productiva y funcional de las ciudades, en función de su integración y/o vinculación con sus entornos regionales y los mercados de bienes y servicios locales, regionales, nacionales e internacionales. Por lo pronto, importantes procesos de cambio aún pueden ser observados en las zonas rurales que circundan la ciudad de Los Ángeles, con la incorporación paulatina de suelos agrícolas al desarrollo urbano, principalmente para usos residenciales, pero también con el surgimiento de pequeños asentamientos urbanos de apoyo, en términos de reserva de mano de obra, a ciertas actividades industriales, como es el caso del sector forestal industrial, agroindustrias y centros de distribución y almacenamiento de recursos naturales. Desde este punto de vista, existen claros elementos de diferenciación social y espacial de estas áreas de borde, de rápido crecimiento en las últimas décadas, respecto de otras áreas urbanas de la ciudad: una mayor complejidad en términos de usos del suelo y orientación productiva; el mantenimiento de estructuras propiamente agrarias y nuevos elementos urbanos; la existencia de reservas de mano de obra; y la valorización económica de espacios rurales sometidos a presiones de cambio de uso del suelo.

En términos generales, el proceso de rápido crecimiento urbano observado en los distritos analizados ocurre a la par con un intenso aumento y movilidad de la población, junto con otra serie de procesos sociodemográficos, como la recomposición de los grupos etarios, su envejecimiento y la aparición de nuevas vulnerabilidades sociales, como los adultos mayores, lo que plantea enormes desafíos a la política y gestión urbana. Entre ellos caben destacar los siguientes: necesidad de establecer mecanismos de planificación local, urbana y rural, que permitan mantener los equilibrios necesarios entre las demandas de suelo urbano y el objetivo estratégico de conservar suelos agrícolas de alta productividad que, en al caso de Los Ángeles, son la base de importantes procesos de producción alimentaria; la necesidad de anticipar estos escenarios de desarrollo urbano y sociodemográfico para luego adaptar los procesos de planificación local, tanto desde el punto de vista espacial como temporal; la necesidad de promover una política integral de desarrollo urbano que considere, como uno de sus elementos centrales, los barrios, y las condiciones sociodemográficas de sus residentes, como un factor esencial de la organización e integración socioespacial de la ciudad. Tales políticas deberán ser necesariamente de carácter multisectorial y combinar coordinadamente no solo acciones sobre las viviendas y el equipamiento urbano sino que también inversiones en educación, salud, capacitación de la mano de obra, accesibilidad, entre otras.

En este contexto, la tesis implícita de muchas investigaciones es que el aumento de la desigualdad socioeconómica de la población tiene su correlato en un mayor grado de polarización socioespacial, supuesto basado en que las regulaciones políticas y de mercado en la asignación del suelo urbano son claves, como también las preferen- 
cias y oportunidades de elección de los individuos. En el caso de Los Ángeles, la dinámica urbana muestra áreas preferenciales para el desarrollo de actividades residenciales e industriales, principalmente en la periferia de zonas urbanas consolidadas, áreas rurales y en torno a ejes viales de importancia comunal y regional. El comportamiento de algunos indicadores sociodemográficos, en zonas urbanas de rápido crecimiento como son los distritos Humán, Arrayán y Avenida Maipú, confirma la tesis de la diferenciación social y espacial. Lo anterior no solo presenta una dimensión física, morfológica o de condiciones de habitabilidad, sino también, y quizás lo más importante, una dimensión socioeconómica y cultural. Ciertas configuraciones sociodemográficas, vulnerabilidades y riesgo social, confluyen o se concentran en ciertas áreas geográficas de la ciudad, afectando no solo la imagen o percepción de otros grupos sociales, sino también la propia imagen o como se perciben a sí mismos sus residentes.

No obstante lo anterior, en los Ángeles, y a pesar de la marcada diferenciación social y espacial de la población, es posible identificar ciertos mecanismos de integración entre grupos sociales, por lo menos en el ámbito laboral, principalmente en el distrito Humán. En la práctica, los remanentes de un antiguo poblamiento agrario, originado en el proceso de Reforma Agraria en los años 70, actúa como una reserva de mano de obra en una zona con un fuerte desarroIlo de proyectos inmobiliarios, generándose una demanda efectiva de empleo y de ciertos bienes, no solo para actividades de construcción, sino también de servicios personales para los residentes de condominios y parcelas de agrado. Respecto de las tendencias sociodemográficas observadas, principalmente en el período 1992-2002, se estima que estas, al igual que en la región del Biobío y el resto del país, tenderán a acentuarse en la ciudad de Los Ángeles, con efectos significativos sobre la distribución generacional del gasto social y con importantes diferenciales entre áreas urbanas y zonas rurales, como ya lo indica el comportamiento del índice de envejecimiento y tasa de crecimiento de la población en los distritos analizados. En otras palabras, se estima que estos indicadores sociodemográfi- cos pueden presentar diferencias significativas entre sectores urbanos ya consolidados y zonas rurales de borde, sometidas a presiones de cambio de uso del suelo, como los distritos Humán, Estación Arrayán y Avenida Maipú.

Finalmente, respecto de los patrones de segregación socioespacial identificados, se estima que los proyectos inmobiliarios para grupos socioeconómicos medios y altos seguirán concentrándose en zonas rurales de borde localizadas al oriente de la ciudad; es decir, en el distrito Humán y que los proyectos de vivienda social lo harán hacia el poniente, en los distritos Estación Arrayán y Avenida Maipú. En este último caso, el segundo bypass de la Ruta 5 Sur y el surgimiento de asentamientos urbanos espontáneos de grandes dimensiones, como la Villa Génesis, permitiría proyectar un área de crecimiento más o menos homogénea, sobre tierras agrícolas que presentan una menor plusvalía en comparación con aquellas localizadas hacia el oriente de la ciudad de Los Ángeles.

* Este artículo es parte de los resultados del proyecto FONDECYT N 1050649 "Modelación del cambio de uso del suelo en la interfase urbano-rural; una herramienta de análisis espacial aplicada al estudio del crecimiento de ciudades intermedias de Chile Central (Chillán y Los Ángeles)".

\section{Referencias bibliográficas}

AGUAYO, M.; WIEGAND, T.; AZÓCAR, G.; WIEGAND, K. \& VEGA, C. Revealing driving forces of mid-cities urban growth patterns using spatial modeling: a case study of Los Angeles (Chile). Ecology and Society, 2007, Vol. 12, No 1, Art. 13. Disponible en Internet: http://www.ecologyandsociety.org/ vol12/iss1/art13/

ANDAUR, C. y PÉREZ, L. Evolución de la Planificación Urbana de Los Ángeles en el Siglo XX. Concepción: Editorial Universidad de Concepción, 2007.

ANTROP, M. Changing patterns in the urbanized countryside of Western Europe. Landscape Ecology, 2000, Vol. 15, No 3, p. 257-270. 
ATRIA, R. Reflexiones acerca del Estado Bienestar para Chile. Transformaciones del Espacio Público. Santiago de Chile: Cátedra Chile-Francia "Michel Foucalt" en Ciencias Sociales, Humanidades, Artes y las Comunicaciones, Universidad de Chile, 2008, p. 173-188.

AZÓCAR, G.; SANHUEZA, R. y HENRÍQUEZ, C. Análisis del cambio en los patrones de crecimiento urbano en una ciudad intermedia de Chile central: un caso de estudio en Chillán. EURE, 2003, Vol. 29, N 87, p. 79-92. Disponible en Internet: http:// redalyc.uaemex.mx/redalyc/pdf/196/ 19608706.pdf

AZÓCAR, G.; ROMERO, H.; SANHUEZA, R.; VEGA, C.; AGUAYO, M. \& MUÑOZ, $M$. Urbanization patterns in chilean mid-sized cities and their impacts on the social restructuring of urban space: a case study in Santa Maria de Los Angeles, Central Chile. Land Use Policy, 2007, Vol. 24, No 1, p. 199-211.

BALBO, M.; JORDÁN, R. y SIMIONI, D. La ciudad inclusiva. Cuadernos de la CEPAL, 2003, N 88. Disponible en Internet: http:// www.eclac.org/publicaciones/xml/7/14237/ lcg2210p.pdf

BORSDORF, A. El desarrollo urbano de Valdivia. Estudio de caso de una ciudad mediana. Espacio y Desarrollo, 2000, № 12, p. 45-82.

BORSDORF, A. Cómo modelar el desarrollo y la dinámica de la ciudad latinoamericana. EURE, 2003, Vol. 29, No 86, p. 3749. Disponible en Internet: http:// redalyc.uaemex.mx/pdf/196/19608602.pdf

BUSSO, G. Vulnerabilidad social: nociones e implicancias de política para Latinoamérica a inicios del siglo XXI. En: Seminario Internacional, La expresión de la vulnerabilidad social en América Latina y el Caribe (Santiago, 20 y 21 de junio de 2001). Santiago de Chile: CEPAL, 2001.

CARRASCO, M. Entrevista personal al Asesor Urbanista Ilustre Municipalidad de Los Ángeles, Arquitecto Plan Regulador 2006. Los Ángeles: marzo, 2006.
CELADE. Redatam. Santiago de Chile: CEPAL, 2001. Disponible en Internet: http:// www.eclac.cl/cedatam/default.asp

DE MATTOS, C. Metropolización y suburbanización. EURE, 2001, Vol. 27, № 80, p. 5-8. Disponible en Internet: http://www. scielo.cl/scielo.php?pid=S0250-7161200100 $8000001 \&$ script $=$ sci_arttext

DE MATTOS, C. Transformación de las ciudades latinoamericanas. ¿Impactos de la globalización? EURE, 2002, Vol. 28, № 85, p. 5-10. Disponible en Internet: http://www. scielo.cl/scielo.php?script=sci_arttext \&pid $=$ S0250-71612002008500001\&Ing $=$ es\&nrm=iso\&tlng=es

DURYEA, S. \& SZÉKELY, M. Labour markets in Latin America: A supply-side story. Washington: Working Paper Series R-374, D.C. BID., 1998. Disponible en Internet: http://www.iadb.org/res/publications/pubfiles/pubWP-374.pdf

FILGUEIRA, C. y PERI, A. América Latina: Los rostros de la pobreza y sus causas determinantes. Santiago de Chile: CEPAL, Serie Población y Desarrollo, 2004, N 54, p. 61.

FLOYSAND, A. \& JAKOBSEN, S. T. Commodification of rural places: A narrative of social fields, rural development and footbaII. Journal of Rural Studies, 2007, Vol. 23, Issue 2, p. 206-221. Disponible en Internet: www.elsevier.com/locate/jrurstud

GONZÁLEZ, M. La fragilidad del medio rural en la expansión urbana de ciudades de rango medio. Algunos alcances para tres ciudades chilenas: Curicó, Talca y Linares. Revista Geográfica Terra Australis, 1994, Nº 39, p. 103-109.

HENRÍQUEZ, C.; AZÓCAR, G. \& ROME$\mathrm{RO}, \mathrm{H}$. Monitoring and modeling the urban growth of two mid-sized Chilean cities. Habitat International, 2006, Vol. 4, No 30, p. 945-964. Disponible en Internet: http:// www.elsevier.com/locate/habitatint

HENRÍQUEZ, C. y AZÓCAR, G. Patrones de crecimiento en ciudades intermedias chilenas y su impacto en la sustentabilidad urbana. En: BELTRÃO, M. E. Cidades Médias: 
Espaços em transição. Sao Paulo: Editora Expressão Popular, 2007, p. 283-312.

HIDALGO, R.; SALAZAR, A.; LAZCANO, R. y ROA, F. Periurbanización y condominios en el área metropolitana de Santiago de Chile. El caso de Pirque y Calera de Tango. Revista Geográfica Terra Australis, 2003, No 48, p. 117-138.

HIDALGO, R. De los pequeños condominios a la ciudad vallada: las urbanizaciones cerradas y la nueva geografía social en Santiago de Chile (1990-2000). EURE, 2004, Vol. 30, No 91, p. 29-52. Disponible en Internet: http://www.scielo.cl/scielo.php?pid=S025071612004009100003 \&script=sci_arttext

HIDALGO, R. y BORSDORF, A. Barrios cerrados y fragmentación urbana en América Latina: Estudio de las transformaciones socioespaciales en Santiago de Chile (19902000), En: HIDALGO, R.; TRUMPER, R. y BORSDORF, A. (Eds.). Transformaciones urbanas y procesos territoriales. Lecturas del nuevo dibujo de la ciudad latinoamericana. Santiago de Chile: Instituto de Geografía, Pontificia Universidad Católica de Chile, Serie GEOLibros, 2005, p. 105-121.

IKONOS. Imágenes Satelitales Multiespectrales. Región de Los Ángeles. EE.UU.: Space Imaging, 2006.

ILPES. La identificación de proyectos y bolsones de pobreza a nivel local. Guía para utilizar la base de datos del censo en REDATAM+. Santiago de Chile: Instituto Latinoamericano y del Caribe de Planificación Económica y Social (ILPES), Dirección de Proyectos y Programación de Inversiones, CEPAL/CELADE, 1995.

Instituto Nacional de Estadísticas (INE). Censo de Población y Vivienda 1992. Santiago de Chile: Instituto Nacional de Estadísticas, 1992.

Instituto Nacional de Estadísticas (INE). Censo de Población y Vivienda 2002. Santiago de Chile: Instituto Nacional de Estadísticas, 2002. Disponible en Internet: http:// www.ine.cl/canales/chile_ estadistico/ c ensos_poblacion_vivienda/ censo_pobl_vivi.php
KAZTMAN, R. Convergencias y divergencias: exploración sobre los efectos de las nuevas modalidades de crecimiento sobre la estructura social de cuatro áreas metropolitanas de América Latina. En: KAZTMAN, R. y WORMALD, G. Trabajo y Ciudadanía: Ios cambiantes rostros de la integración y la exclusión social en cuatro áreas metropolitanas en América Latina. Montevideo: Cebra, 2002, p. 23-60.

MAGNO DE CARVALHO, J. A. The demographic of poverty and welfare in Latin America: Challenges and opportunities. En: TOKMAN, V. \& O'DONNELL, G. Poverty and inequality in Latin America: Issues and new challenges. Indiana: University of Notre Dame Press, 1998.

MIDEPLAN. Encuesta CASEN 2003. Santiago de Chile: MIDEPLAN, 2005.

ORTIZ, J. y MORALES, S. Impacto socioespacial de las migraciones intraurbanas en entidades de centro y nuevas periferias del Gran Santiago. EURE, 2002, Vol. 28, No 85, p. 117-185. Disponible en Internet: http:// www.scielo.cl/scielo.php?pid=S0250$71612002008500009 \&$ script $=$ sci_arttext

PINTO DA CUNHA, J. Urbanización, redistribución espacial de la población y transformación socioeconómica en América Latina. Santiago de Chile: CEPAL, Serie Población y Desarrollo, 2002, N 30.

RODRÍGUEZ, J. Segregación residencial socioeconómica: ¿Qué es? ¿Cómo se mide? ¿Qué está pasando? ¿Importa? Santiago de Chile: CEPAL, Serie Población y Desarrollo, 2001, N 16.

RODRÍGUEZ, J. y VILLA, M. Distribución espacial de la población, urbanización y ciudades intermedias: hechos en su contexto. En: JORDÁN, R. y SIMIONI, D. (Eds.). Ciudades intermedias en América Latina y el Caribe. Santiago de Chile: Comisión Económica para América Latina y el Caribe (CEPAL) - Ministero degli Affari Esteri Cooperazione Italiana, 1998, p. 25-68.

ROJAS, J.; AZÓCAR, G.; MUÑOZ, M. D.; VEGA, C.; KINDLER, A. y KABISCH, S. Atlas Social y Ambiental del Área Metropoli- 
tana de Concepción, Región del Biobío, Chile: Transformaciones sociodemográficas y ambientales 1992-2002. Concepción: Editorial Universidad de Concepción, 2006.

ROMERO, H. Amenity migration in Latin America. En: PRICE, M. Global Change in Mountain Regions. Duncow, UK: Sapiensa Publishing, 2006, p. 321-322.

ROMERO, H. y TOLEDO, X. Crecimiento económico y desigualdades regionales en Chile; indicadores de evaluación ambiental estratégica. Anales de la Sociedad Chilena de Ciencias Geográficas, 1998, p. 537-570.

ROMERO, H.; HENRÍQUEZ, C.; AZÓCAR, G.; VÁSQUEZ, A.; SOUZA, N.; RIVEROS, A. y MORÁN, A. Sistemas de Información Geográfica para el Desarrollo Sustentable de las ciudades chilenas. En: U. DEL BÍO-BÍO. Segundo Congreso Internacional Ciudad y Territorio Virtual. Libro de Ponencias. Concepción: U. del Bío-Bío, 2005, p. 52-58. Disponible en Internet: http://www.facd.ubiobio.cl/2ctv/espanol.htm

ROVIRA, A. Puerto Montt: El paso de una ciudad menor a centro de desarrollo interregional en una ciudad del Sur de Chile. Espacio y Desarrollo, 2000, No 12, p. 83-102.

SABATINI, F. Direcciones para el futuro. En: JORDÁN, R. y SIMIONI, D. (Eds.). Ciudades intermedias en América Latina y el Caribe. Santiago de Chile: Comisión Económica para América Latina y el Caribe (CEPAL) - Ministero degli Affari Esteri Cooperazione Italiana, 1998, p. 127-214.
SABATINI, F. Reforma de los mercados de suelo en Santiago de Chile: efectos sobre los precios de la tierra y la segregación residencial. EURE, 2000, Vol. 26, No 77, p. 4980. Disponible en Internet: http:// www.scielo.cl/scielo.php?pid=S0250$71612000007700003 \&$ script $=$ sci_arttext

SAG. Planos de loteos proyectos de subdivisión de predios rústicos comuna de Los Ángeles. Los Ángeles: Oficina Provincial SAG, 2006.

SEGURA, D. El sentido del bienestar en una política social de vivienda: El caso de la fase piloto del Chile Barrio. Scripta Nova, 2003, Vol. 7, No 146, Art. 89. Disponible en Internet: http://www.ub.es/geocrit/sn/sn146(089).htm

SOTO, G. y ULLOA, F. Diagnóstico de la Desertificación en Chile. La Serena: Universidad de Chile - Programa FAO/PNUMA Ministerio de Agricultura - Corporación Nacional Forestal (CONAF), 1997.

TOLEDO, X.; ROMERO, H. y MARÍN, A. Segregación socioespacial en la comuna de Temuco. Espacio y Desarrollo, 2000, №, 12, p. 104-122.

ZUNINO, H., Construyendo ciudad desde lo local en lo global: El caso del proyecto Ribera Norte, Chile. Scripta Nova, 2005, Vol. 9, No 194, Art. 86. Disponible en Internet: http://www.ub.es/geocrit/sn/sn-19486.htm 